\title{
Influence of Road Roughness Wavelengths on Bus Passengers' Oscillatory Comfort
}

\author{
Dragan Sekulić \\ University of Belgrade, Faculty of Transport and Traffic Engineering, Belgrade 11000, Serbia.
}

\begin{abstract}
(Received 26 April 2018; accepted 19 March 2019)
\end{abstract}
This paper analyses the effect of the waviness parameter $w$ on the oscillatory comfort of bus passengers for one road in good condition. The analysis is carried out by a validated nonlinear oscillatory 16 degrees of freedom (DOF) bus model defined in the software Matlab/Simulink and procedure from ISO 2631/1997 standard. The root-mean-square $(R M S)$ values of the weighted vertical accelerations from the passengers' seats increase with the increase in the parameter $w$. On the other hand, the $R M S$ values of the weighted vertical accelerations from bus floor decreased with the increase in the parameter $w$. The best oscillatory comfort has a passenger in the middle part of the bus, and the worst has a passenger in the rear part of the bus. The intensities of the vertical accelerations from the bus floor are mainly concentrated into two frequency ranges, $0 \div 2.5 \mathrm{~Hz}$ and $5 \div 10 \mathrm{~Hz}$. The passenger seats are dampened with vertical vibrations above $4 \mathrm{~Hz}$. For the narrow range $w=1.5 \div 2.3$, nominal value of the waviness parameter $(w=2)$ is sufficiently precise in assessment of the bus passengers' oscillatory comfort.

\section{INTRODUCTION}

The oscillatory movement of the bus negatively affects bus users' oscillatory comfort, road surface, and the vehicle itself. Although bus oscillatory motion is excited from a number of sources, the dominant excitation originates from road roughness. Longitudinal road roughness comprises of a number of different unevenness, wavelengths, and amplitudes. Spectrum composition and unevenness amplitude, and their effect on the vibration intensity, depend on the type/condition of the road roughness and on vehicle speed.

There are a considerable number of direct and indirect parameters for the description of the longitudinal road roughness. ${ }^{1}$ Direct parameters come from vertical road elevation data processing. Two of these parameters refer to road elevation power spectral density (PSD) - unevenness index $\Phi_{\zeta}\left(n_{0}\right)$ and waviness parameter $w .^{2}$ Standard ISO 8608 analytically defines PSD and presents a classification of road roughness according to different unevenness index $\Phi_{\zeta}\left(n_{0}\right)$ values and one constant waviness $w$ value $(w=2)$.

The unevenness index defines road roughness quality. Higher values of the unevenness coefficient indicate a worse state of the road. The waviness parameter expresses distribution of short/long wavelengths in road elevation spectrum. According to the ISO 8608 standard, the nominal value of parameter $w$ is 2 and indicates a similar proportion of short/long wavelengths in the road spectrum. However, studies have shown that the values of the parameter w lie within the limits of 1.5 to $3.5 .^{3}$ Standard shape of the PSD with waviness of $w=2$ correspond to $60 \%$ of analysed road profiles. Long wavelengths $(w>2)$ prevailed in $20 \%$, and for the remaining $20 \%$, short wavelengths $(w<2)$ dominated. ${ }^{4}$

Múčka analysed influence of the longitudinal road unevenness on the dynamic tire forces using the quarter model of a commercial heavy vehicle with $2 \mathrm{DOF}^{4}$ Dynamic tyre forces in function of random road profiles with different waviness using longitudinal planar model of three axle heavy vehicle with 8 DOF were analysed by Múčka. ${ }^{5}$ Four different spatial mathematical models of heavy vehicles are used for simulation when analysing influence of different roads roughness and waviness on dynamic load stress factor by Steinauer and Ueckermann. ${ }^{6}$ To the author's knowledge, influence of road waviness on the bus vertical dynamics, especially on passengers' ride comfort, is not a sufficiently investigated area.

The aim of this paper is to determine the influence of the waviness parameter $w$ on bus passengers' whole-body vibration (WBV) considering vertical accelerations from their seats. The aim is also to determine the effect of the parameter $w$ on vertical acceleration from bus floor acting on the passenger's legs. The main goal of this work is to determine passengers' ride comfort in the function of the parameter $w$. In order to achieve these goals, a validated nonlinear in-plane bus model with 16 DOF was considered. The model was defined in the Matlab/Simulink software. Longitudinal road roughness in good condition was modelled by road elevation PSD defined in ISO 8608 standard. Ride comfort was determined by procedure and criteria prescribed by ISO 2631/1997 standard. This standard is the most frequently used one when assessing human response to $\mathrm{WBV}^{7}$

\section{BUS OSCILLATORY MODEL}

Figure 1 shows intercity bus IK-301 for passengers transport. Elementary geometry parameters are shown in Fig. 1(a). Position of the passengers' seats $(1 \div 3)$, considered in the oscillatory comfort analysis are denoted in Fig. 1(a, b). Figure 1(b) also indicates layout of the bus seats.

A sixteen DOF plane model of the intercity bus IK-301 was used in the study (Fig. 2). The DOF included mass $m_{h i},(i=$ $1 \div 3$ ) bouncing $\left(z_{h i},(i=1 \div 3)\right)$, mass $m_{c i},(i=1 \div 3)$ bouncing $\left(z_{c i},(i=1 \div 3)\right)$, mass $m_{l t i},(i=1 \div 3)$ bouncing $\left(z_{l t i},(i=1 \div 3)\right)$, mass $m_{t p i},(i=1 \div 3)$ bouncing $\left(z_{t p i}\right.$, $(i=1 \div 3)$ ), mass $m$ (vehicle body) bouncing $(z)$, mass $m$ (vehicle body) pitching $(\theta)$, mass $m_{t 1}$ (front axle) bouncing $\left(z_{t 1}\right)$, and mass $m_{t 2}$ (rear axle) bouncing $\left(z_{t 2}\right)$.

When forming the bus oscillatory model, the next assumptions were considered:

- the bus body, front and rear axles are rigid bodies; 


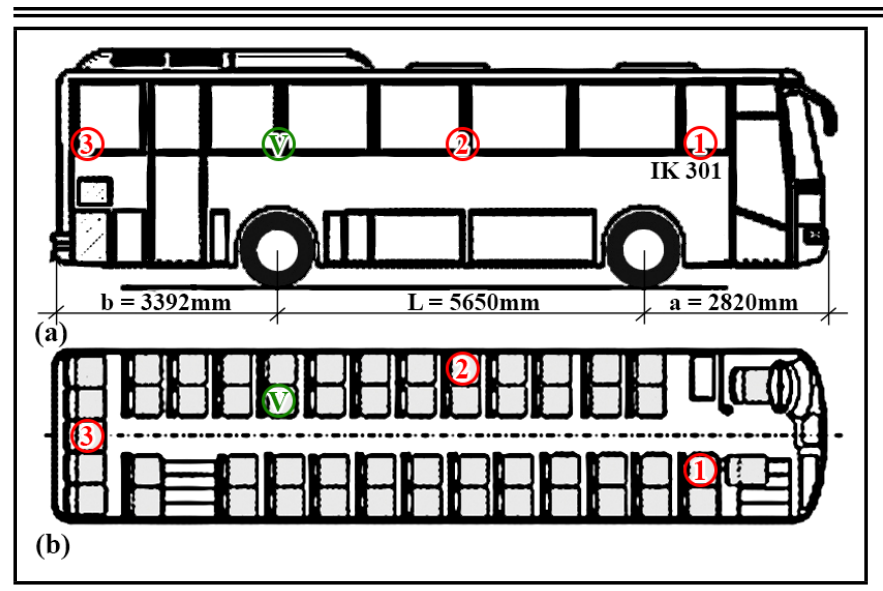

Figure 1. Bus IK-301 a) elementary geometry parameters ( $L$-wheelbase; $a$-front overhang; $b$-rear overhang), b) position of the passengers' seats for ride comfort analysis.

- the bus is symmetrical relative to the longitudinal centre of gravity axis ( $x$-axis);

- there are no angular movements around $x$-axis;

- the excitations on both left and right wheels are the same;

- contact between wheel and road is in one point;

- characteristics of all elastic elements are linear;

- the bus is moving along a straight line with constant speed.

Bus IK-301 had two wheels on the front axle and two twin wheels at the rear axle. ${ }^{8}$ The front axle suspension comprised of two air springs and four telescopic shock absorbers, while on the rear axle, it included four air springs and four telescopic shock absorbers. ${ }^{8}$

The differential equations of motion, by applying Lagrange's equations of motion of second kind, for oscillatory model are given by Eqs. (1-10):

$$
\begin{aligned}
& m_{h i} \ddot{z}_{h i}+c_{1} \dot{z}_{h i}+k_{1} z_{h i}-c_{1} \dot{z}_{c i}-k_{1} z_{c i}=0, \quad(i=1 \div 3) \\
& m_{c i} \ddot{z}_{c i}+\left(c_{1}+c_{2}\right) \dot{z}_{c i}+\left(k_{1}+k_{2}\right) z_{c i}-c_{1} \dot{z}_{h i}-k_{1} z_{h i}- \\
& c_{2} \dot{z}_{l t i}-k_{2} z_{l t i}=0, \quad(i=1 \div 3) ; \\
& m_{l t i} \ddot{z}_{l t i}+\left(c_{2}+c_{3}\right) \dot{z}_{l t i}+\left(k_{2}+k_{3}\right) z_{l t i}-c_{2} \dot{z}_{c i}-k_{2} z_{c i}- \\
& c_{3} \dot{z}_{t p i}-k_{3} z_{t p i}=0, \quad(i=1 \div 3) \\
& m_{t p 1} \ddot{z}_{t p 1}+\left(c_{3}+c_{4}^{\prime}\right) \dot{z}_{t p 1}+\left(k_{3}+k_{4}^{\prime}\right) z_{t p 1}-c_{3} \dot{z}_{l t 1}- \\
& k_{3} z_{l t 1}-c_{4}^{\prime} \dot{z}-k_{4}^{\prime} z-c_{4}^{\prime} d_{1} \dot{\theta}-k_{4}^{\prime} d_{1} \theta=0 ; \\
& m_{t p 2} \ddot{z}_{t p 2}+\left(c_{3}+c_{4}^{\prime}\right) \dot{z}_{t p 2}+\left(k_{3}+k_{4}^{\prime}\right) z_{t p 2}-c_{3} \dot{z}_{l t 2}- \\
& k_{3} z_{l t 2}-c_{4}^{\prime} \dot{z}-k_{4}^{\prime} z-c_{4}^{\prime} d_{2} \dot{\theta}-k_{4}^{\prime} d_{2} \theta=0 ; \\
& m_{t p 3} \ddot{z}_{t p 3}+\left(c_{3}+c_{4}^{\prime}\right) \dot{z}_{t p 3}+\left(k_{3}+k_{4}^{\prime}\right) z_{t p 3}-c_{3} \dot{z}_{l t 3}- \\
& k_{3} z_{l t 3}-c_{4}^{\prime} \dot{z}-k_{4}^{\prime} z-c_{4}^{\prime} d_{3} \dot{\theta}-k_{4}^{\prime} d_{3} \theta=0 \text {; } \\
& m \ddot{z}+3 c_{4}^{\prime} \dot{z}+\left(3 k_{4}^{\prime}+k_{f}+k_{r}\right) z+\left(d_{1}+d_{2}-d_{3}\right) c_{4}^{\prime} \dot{\theta}+ \\
& \left(k_{4}^{\prime} d_{1}+k_{4}^{\prime} d_{2}-k_{4}^{\prime} d_{3}+k_{f} a-k_{r} b\right) \theta-c_{4}^{\prime} \dot{z}_{t p 1}-k_{4}^{\prime} z_{t p 1}- \\
& c_{4}^{\prime} \dot{z}_{t p 2}-k_{4}^{\prime} z_{t p 2}-c_{4}^{\prime} \dot{z}_{t p 3}-k_{4}^{\prime} z_{t p 3}-k_{f} z_{t 1}-k_{r} z_{t 2}+ \\
& F_{f_{-} e q}\left(\Delta \dot{z}_{f}\right)+F_{r_{-} e q}\left(\Delta \dot{z}_{r}\right)=0
\end{aligned}
$$

$$
\begin{aligned}
& J_{y} \ddot{\theta}+\left(d_{1}^{2}+d_{2}^{2}+d_{3}^{2}\right) c_{4}^{\prime} \dot{\theta}+\left(d_{1}^{2} k_{4}^{\prime}+d_{2}^{2} k_{4}^{\prime}+d_{3}^{2} k_{4}^{\prime}+\right. \\
& \left.a^{2} k_{f}+b^{2} k_{r}\right) \theta+\left(d_{1}+d_{2}-d_{3}\right) c_{4}^{\prime} \dot{z}+\left(d_{1} k_{4}^{\prime}+d_{2} k_{4}^{\prime}-\right. \\
& \left.d_{3} k_{4}^{\prime}+a k_{f}-b k_{r}\right) z-d_{1} c_{4}^{\prime} \dot{z}_{t p 1}-d_{1} k_{4}^{\prime} z_{t p 1}-d_{2} c_{4}^{\prime} \dot{z}_{t p 2}- \\
& d_{2} k_{4}^{\prime} z_{t p 2}+d_{3} c_{4}^{\prime} \dot{z}_{t p 3}+d_{3} k_{4}^{\prime} z_{t p 3}-a k_{f} z_{t 1}+b k_{r} z_{t 2}+ \\
& a F_{f-e q}\left(\Delta \dot{z}_{f}\right)-b F_{r_{-e q}}\left(\Delta \dot{z}_{r}\right)=0 ; \\
& m_{t 1} \ddot{z}_{t 1}+c_{f t} \dot{z}_{t 1}+\left(k_{f t}+k_{f}\right) z_{t 1}-k_{f} z-a k_{f} \theta- \\
& \quad F_{f-e q}\left(\Delta \dot{z}_{f}\right)=c_{f t} \dot{\zeta}_{1}+k_{f t} \zeta_{1} ; \\
& m_{t 2} \ddot{z}_{t 2}+c_{r t} \dot{z}_{t 2}+\left(k_{r t}+k_{r}\right) z_{t 2}-k_{r} z+b k_{r} \theta- \\
& \quad F_{r_{-} e q}\left(\Delta \dot{z}_{r}\right)=c_{r t} \dot{\zeta}_{2}+k_{r t} \zeta_{2} .
\end{aligned}
$$

The sets $F_{f_{-} e q}\left(\Delta \dot{z}_{f}\right)$ and $F_{r_{-} e q}\left(\Delta \dot{z}_{r}\right)$ represented nonlinear equivalent damping forces of the shock absorbers on the front and rear axles of the bus (Eqs. (7-10)). The damping forces depended on the relative piston velocity in the shock absorber cylinder, (Eqs. (11) and (12)):

$$
\begin{aligned}
& \Delta \dot{z}_{f}=v_{f}=\dot{z}_{D}-\dot{z}_{t 1}=\dot{z}+a \dot{\theta}-\dot{z}_{t 1} \\
& \Delta \dot{z}_{r}=v_{r}=\dot{z}_{E}-\dot{z}_{t 2}=\dot{z}-b \dot{\theta}-\dot{z}_{t 2} .
\end{aligned}
$$

Figure 3 shows the piecewise linear curves that represented characteristics for one damper on front/rear axle, as well as their equivalent characteristics. Piecewise linear curves have been used for modelling of experimentally established nonlinear damper properties. ${ }^{9}$ Nonlinear characteristics of the individual shock absorber are described analytically (Eqs. (13) and (14)). The equivalent characteristics of the shock absorber were loaded into the oscillatory model using the Simulink function 'Lookup table'. The damping force was considerably greater in the rebound mode, compared to the compression mode of the shock absorber (Fig. 3).

$$
\begin{aligned}
& F_{f}\left(v_{f}\right)= \begin{cases}c_{f 1} v_{f}, & 0 \leq v_{f}<0.16 ; \\
c_{f 2} v_{f}+1850, & 0.16 \leq v_{f} \leq 1 ; \\
c_{f 3} v_{f}, & -1 \leq v_{f}<0 ;\end{cases} \\
& F_{r}\left(v_{r}\right)= \begin{cases}c_{r 1} v_{r}, & 0 \leq v_{r}<0.3 ; \\
c_{r 2} v_{r}+2800, & 0.3 \leq v_{r} \leq 1 ; \\
c_{r 3} v_{r}, & -1 \leq v_{r}<0 .\end{cases}
\end{aligned}
$$

Values of damping coefficients for each shock absorber, equivalent damping coefficients and transition speeds for both axles are given in Table 1.

The WBV bus passenger's exposure analysis was performed using a linear seat-human model (Fig. 2). Linear biodynamic human body 4 DOF model proposed by Boileau was used when defining a seat-human model. ${ }^{10}$ Connection between the passenger body and the seat was represented by an elasticdamping element with an equivalent coefficient of stiffness $k_{4}^{\prime}$ and an equivalent coefficient of damping $c_{4}^{\prime}$. Equivalent coefficients were determined based on the serial connection between seat cushion and human buttocks oscillatory parameters, (Eqs. (15) and (16)).

$$
\begin{aligned}
k_{4}^{\prime} & =\frac{k_{1} \cdot k 4}{k_{1}+k_{4}} ; \\
c_{4}^{\prime} & =\frac{c_{1} \cdot c 4}{c_{1}+c_{4}} .
\end{aligned}
$$

The passenger seats did not have an elastic suspension system and were stiff-suspended on the bus body. Vibration 


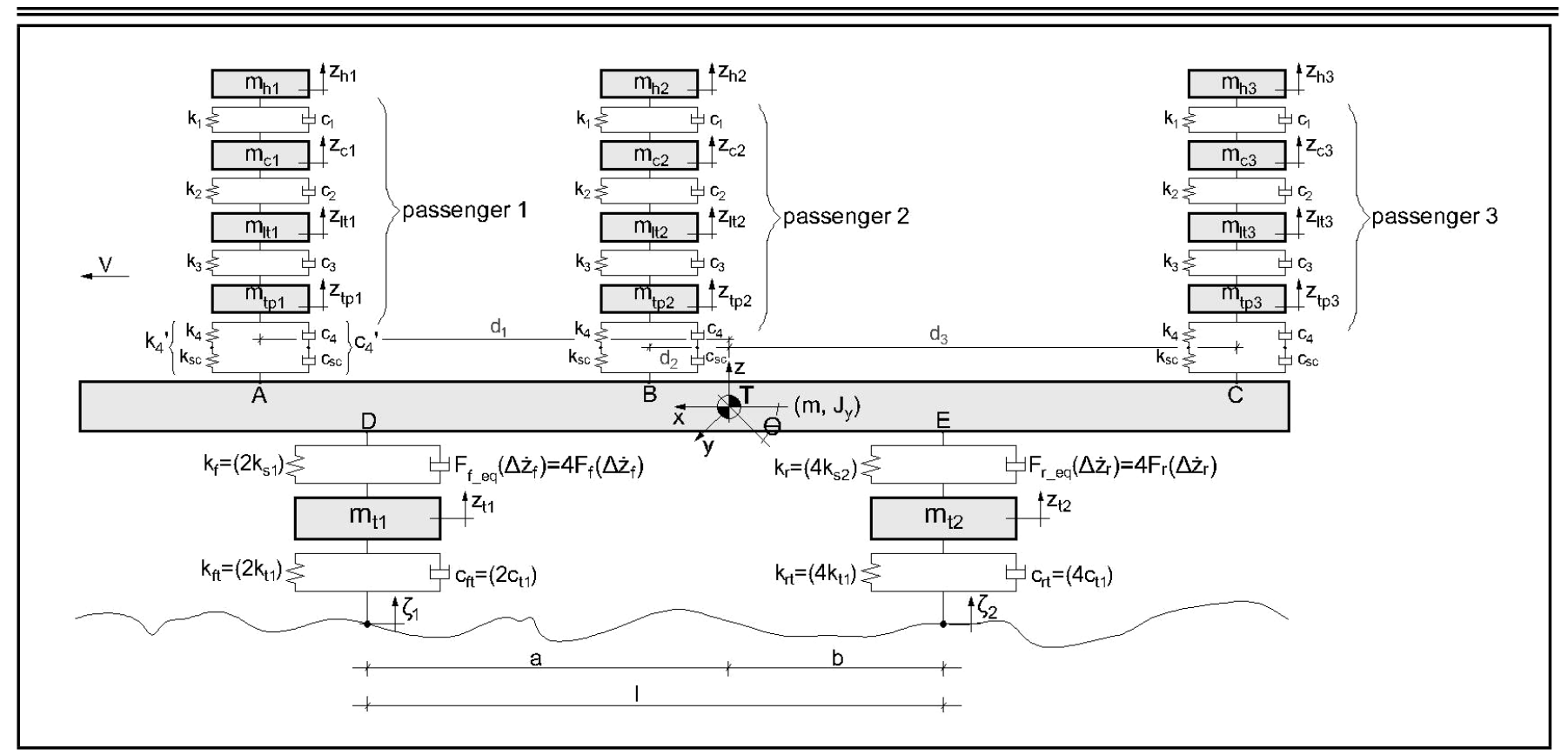

Figure 2. In-plane oscillatory bus model with 16 DOF.

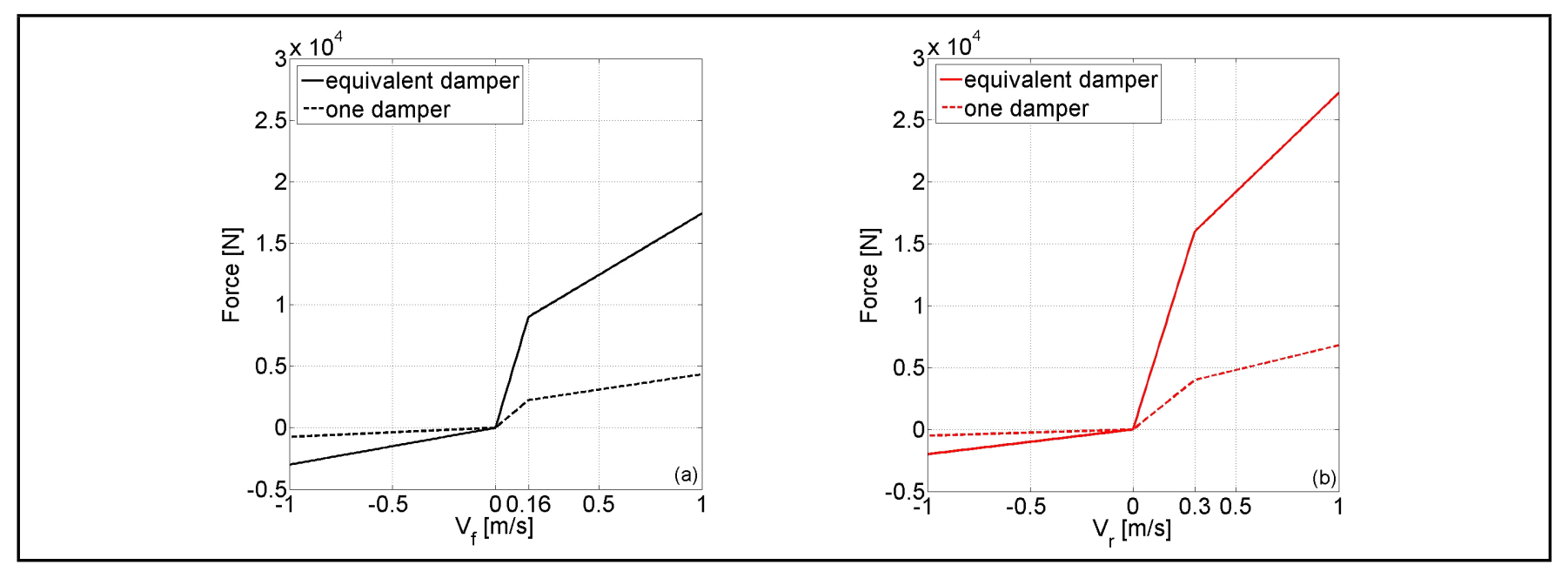

Figure 3. Damper force-velocity characteristics for a) front axle, b) rear axle.

damping was performed by foam seat cushions. Seat cushion stiffness/damping coefficients originated from available literature. $^{11,12}$ Table 3 shows the parameter values for the linear seat-human oscillatory model, according to Boileau. ${ }^{10}$ Figure 4 shows top level Simulink diagram of the bus oscillatory model. The Matlab built-in function 'ode45' with a variable step-size was used for numerical integration. The defined initial conditions for all variables were set to zero. The chosen simulation time was 7 seconds.

Parameters from differential equations and their values are shown in Table 2, and originated from the available literature. ${ }^{8,11}$

\subsection{Validation of the Bus Oscillatory Model}

Bus model validation was based on acceleration signals measured in bus IK-301 during real exploitation condition. ${ }^{13}$ A total of 14 measurements were carried out on three different types of road (asphalt-concrete/macadam/cube pavement) in three different states (bad/medium/good) and at five different bus speeds (40,60, 80, 100 and $130 \mathrm{~km} / \mathrm{h}$ ).

The bus model was validated by two different oscillatory quantities from MEASUREMENT 11: vertical acceleration on the passenger seat surface positioned above rear axle and vertical accelerations on the floor below passenger's seat. The position of the passenger's seat was denoted with V in Fig. 1(ab). The measurement of these signals was carried out on the empty intercity bus IK-301 on sections of the 'Airport-Ikarbus' asphalt-concrete road in a good condition. ${ }^{13}$ The bus was moving at a speed of $100 \mathrm{~km} / \mathrm{h}$. A driver, one passenger, and two persons for data collection participated in the measurements. The acceleration signal was registered on the surface of the passenger's seat positioned over the rear axle, with the passenger seated on the seat, below the passenger's body.

A WBV tri-axial seat pad accelerometer (B\&K type 4321) registered vertical acceleration signal on passenger's seat (Fig. 5(a)). A B\&K type 2635 amplifier was used to amplify the output signal from the accelerometer (Fig. 5(b)). An inductive accelerometer (HBM type B12/200) registered vertical acceleration signals from the bus floor below passenger's seat (Fig. 5(c)). Signals were recorded during $13.65 \mathrm{~s}$.

Real road roughness in good condition was introduced in the bus oscillatory model when performing simulation for the 


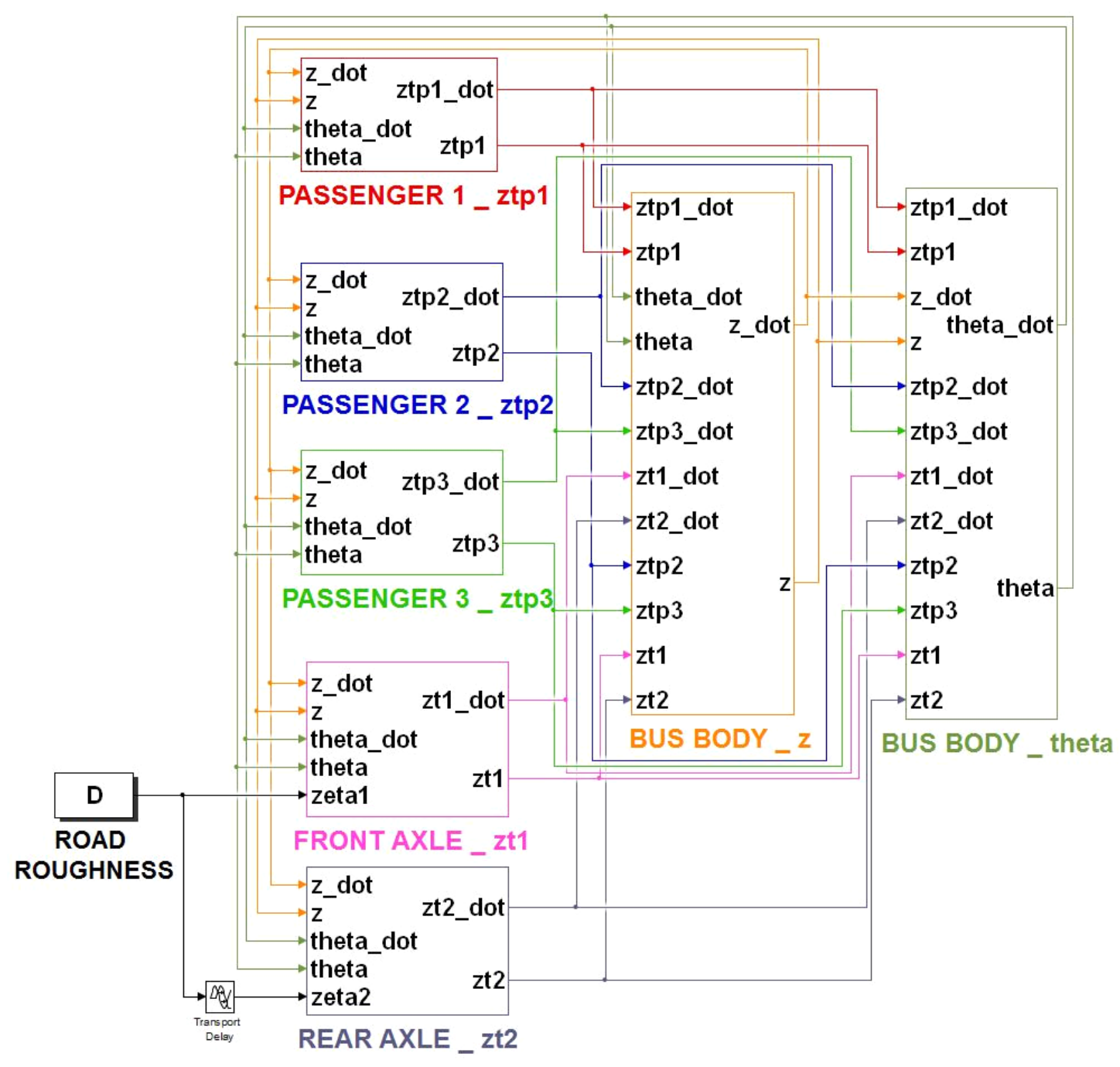

Figure 4. Top level Simulink diagram of the bus oscillatory model with 16 DOF.
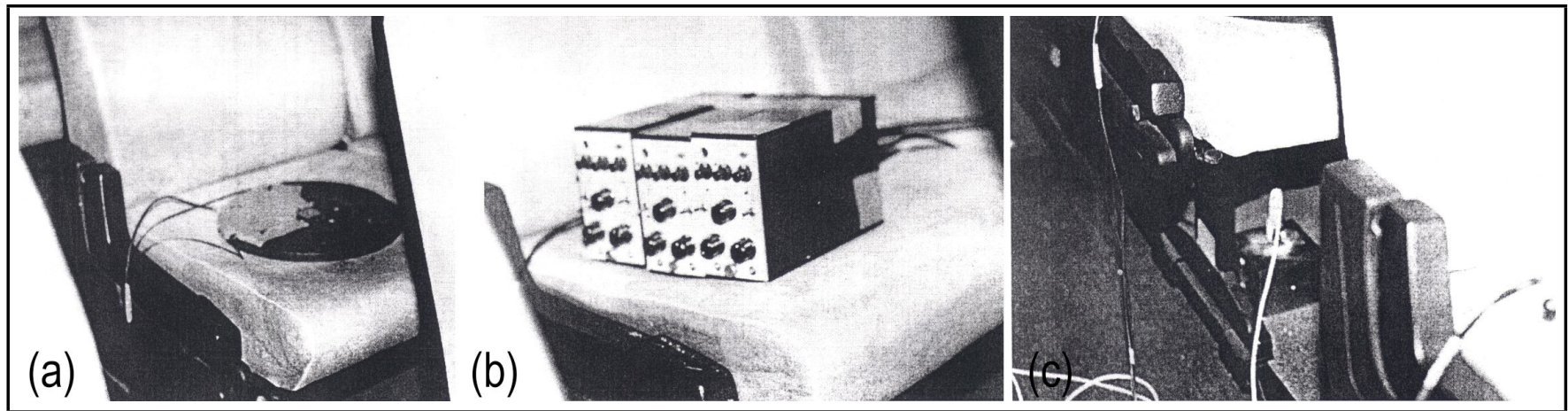

Figure 5. Measuring equipment a) tri-axial seat pad accelerometer, b) an amplifier, c) inductive accelerometer.

purpose of validation process (Fig. 6). The measuring vehicle registered roughness along a single track on a $200 \mathrm{~m}$ road section. Roughness was registered every $0.025 \mathrm{~m}$ at the speed of $90 \mathrm{~km} / \mathrm{h} .{ }^{14}$ Figure 6 shows the asphalt-concrete road roughness in a good condition as a function of time.

Figure 7 shows vertical acceleration signals on the passenger's seat surface and on the bus floor below passenger's seat determined by measurements and simulation. With the Fig. 7(b), the acceleration of $10 \mathrm{~m} / \mathrm{s}^{2}$ corresponds to the volt- age of $1 \mathrm{~V}$.

The measured and simulated vertical acceleration signals were similar in their magnitudes, but with some differences in the frequencies (Fig. 7(a-b)). The statistical values (maximum, minimum, mean value, and dispersion) slightly differed for simulation and experimental data (Table 4). The results showed correlation, although the acceleration signals were registered on the road section of the same type and condition, but not at the same location. Besides the road excitation dif- 


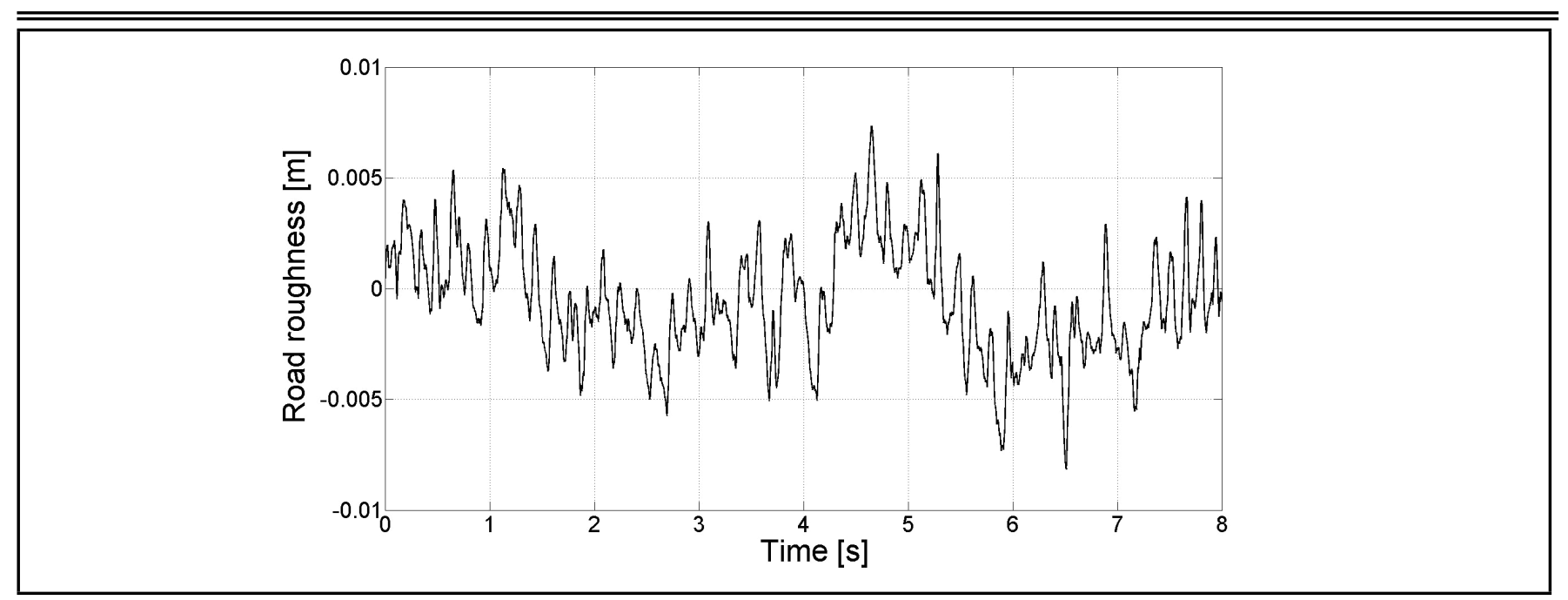

Figure 6. Real road roughness of asphalt-concrete pavement in good condition registered at speed of $90 \mathrm{~km} / \mathrm{h}$.

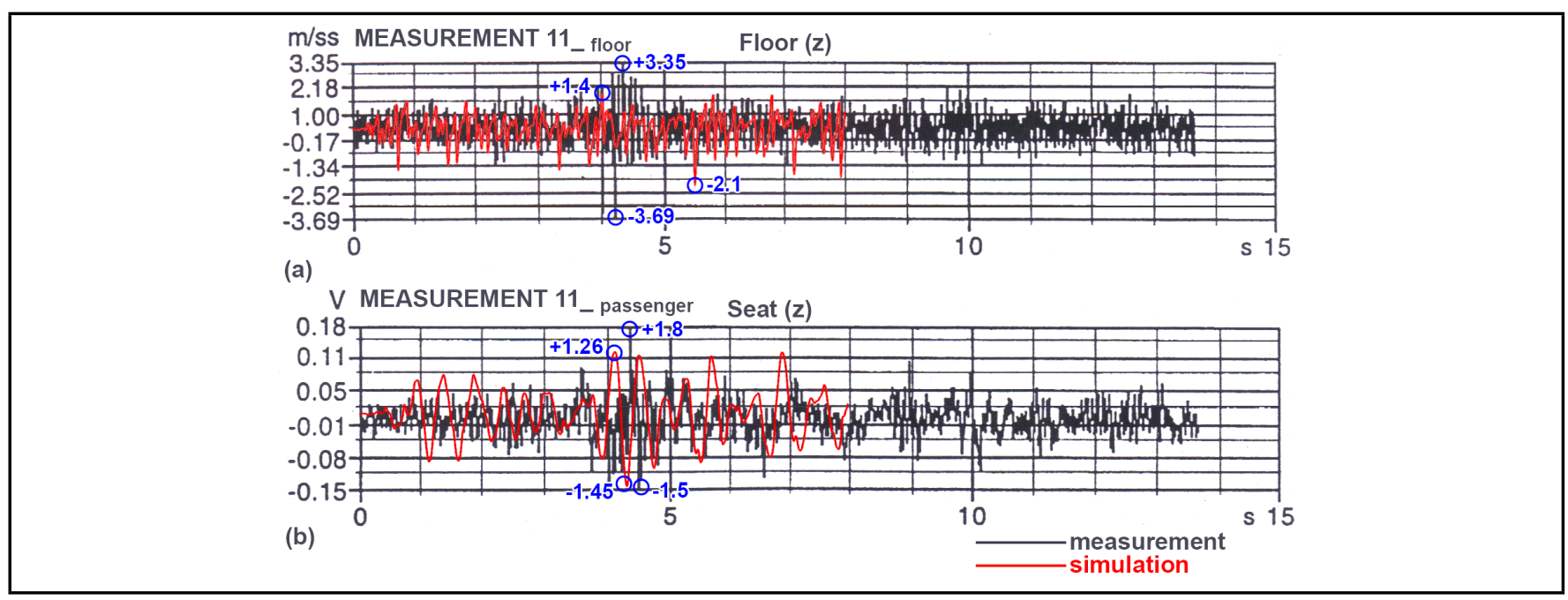

Figure 7. Measured and simulated vertical acceleration signal for a) bus floor below passenger's seat, b) passenger's seat above rear axle.

Table 1. Damping coefficients and transitions speeds of shock absorbers for front/rear axle.

\begin{tabular}{|l|c|}
\hline Front axle - Parameter & Value \\
\hline Low speed rebound mode damping coefficient $c_{f 1}(\mathrm{Ns} / \mathrm{m})$ & 14062.5 \\
Equivalent low speed rebound mode damping coefficient & 56250 \\
$\left(4 \cdot c_{f 1}\right)(\mathrm{Ns} / \mathrm{m})$ & 2500 \\
High speed rebound mode damping coefficient $c_{f 2}(\mathrm{Ns} / \mathrm{m})$ & 10000 \\
Equivalent high speed rebound mode damping coefficient \\
$\left(4 \cdot c_{f 2}\right)(\mathrm{Ns} / \mathrm{m})$ \\
High speed rebound mode damping coefficient $c_{f 3}(\mathrm{Ns} / \mathrm{m})$ & 750 \\
Equivalent high speed rebound mode damping coefficient & 3000 \\
$\left(4 \cdot c_{f 3}\right)(\mathrm{Ns} / \mathrm{m})$ & 0.16 \\
Transition velocity $v_{f e}(\mathrm{~m} / \mathrm{s})$ & Value \\
\hline Rear axle - Parameter & 13333.3 \\
\hline Low speed rebound mode damping coefficient $c_{r 1}(\mathrm{Ns} / \mathrm{m})$ & 53333.3 \\
Equivalent low speed rebound mode damping coefficient \\
$\left(4 \cdot c_{r}\right)(\mathrm{Ns} / \mathrm{m})$ \\
High speed rebound mode damping coefficient $c_{r 2}(\mathrm{Ns} / \mathrm{m})$ \\
Equivalent high speed rebound mode damping coefficient \\
$\left(4 \cdot c_{r 2}\right)(\mathrm{Ns} / \mathrm{m})$ & 4000 \\
High speed rebound mode damping coefficient $c_{r 3}(\mathrm{Ns} / \mathrm{m})$ & 16000 \\
Equivalent high speed rebound mode damping coefficient & 500 \\
$\left(4 \cdot c_{r}\right)(\mathrm{Ns} / \mathrm{m})$ & 2000 \\
Transition velocity $v_{r e}(\mathrm{~m} / \mathrm{s})$ & 0.3 \\
\hline
\end{tabular}

ferences, some simplifications referring to the bus oscillatory model might affect simulation results (such as using an inplane and not space bus model, linear characteristics of elastic elements, point wheel-road contact, etc.).

\section{BUS MODEL EXCITATION}

Unevenness PSD defined in ISO 8608 was used for road roughness modeling (Eq. (17)).

$$
\Phi_{\zeta}(n)=\Phi_{\zeta}\left(n_{0}\right) \cdot\left(\frac{n}{n_{0}}\right)^{-w} ;
$$

where $\Phi_{\zeta}(n)$-PSD of road roughness $\left(\mathrm{m}^{2} /(\right.$ cycles $\left./ \mathrm{m})\right)$; $\Phi_{\zeta}\left(n_{0}\right)$ - unevenness index $\left(\mathrm{m}^{2} /(\right.$ cycles $\left./ \mathrm{m})\right) ; n_{0}$-reference spatial frequency $\left(n_{0}=0.1(\right.$ cycles $\left./ \mathrm{m})\right) ; w$-waviness $(-)$. Figure 8 shows the PSD in the function of spatial frequency for different road roughness conditions.

ISO 8608 presented a classification of road roughness according to different unevenness index values and for one constant waviness value $w=2$. The unevenness index denoted road roughness quality, and defined the ordinate position of the PSD function (Fig. 8). The value of the unevenness index for a road in good condition (A/B - ISO level class) is $32 \cdot 10^{6} \mathrm{~m}^{2} /($ cycles $/ \mathrm{m}){ }^{2}$ Although the PSDs in ISO 8608 were defined for standard constant waviness value, measurements in the United States, Germany, and Sweden revealed that waviness parameter frequently has a value in a rather wide range $1.5 \div 3.5^{3,15}$

The connection between the temporal and spatial frequency as well as the corresponding PSDs can be represented by 


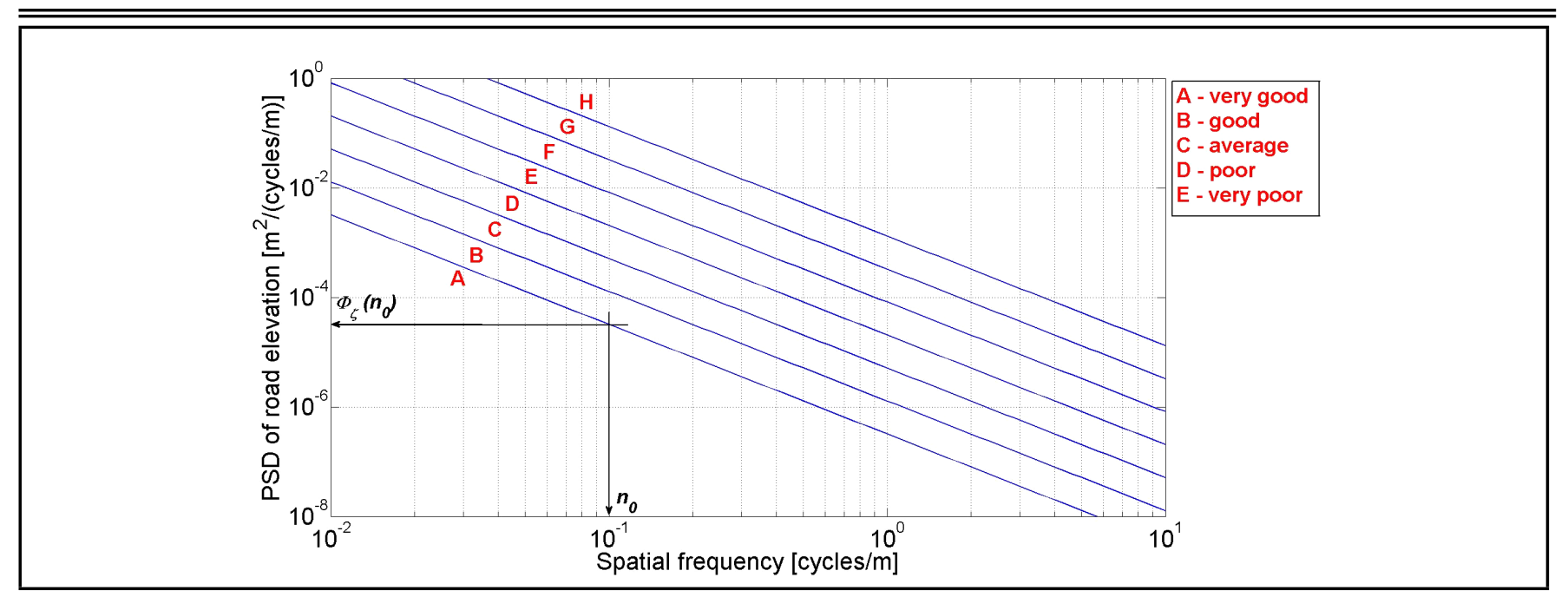

Figure 8. PSD for different road roughness quality and constant waviness parameter value $(w=2)$.

Table 2. Bus IK-301 oscillatory model parameters used in simulation.

\begin{tabular}{|c|c|}
\hline Geometric parameters of the bus & Values \\
\hline Wheelbase $l(\mathrm{~m})$ & 5.65 \\
\hline $\begin{array}{l}\text { Distance from front axle to centre of gravity of } \\
\text { loaded/empty bus } a(\mathrm{~m})\end{array}$ & $3.55 / 3.70$ \\
\hline $\begin{array}{l}\text { Distance from rear axle to centre of gravity of } \\
\text { loaded/empty bus } b(\mathrm{~m})\end{array}$ & $2.10 / 1.95$ \\
\hline $\begin{array}{l}\text { Distance from passenger1's seat to centre of gravity } \\
d_{1}(\mathrm{~m})\end{array}$ & 4.60 \\
\hline $\begin{array}{l}\text { Distance from passenger2's seat to centre of gravity } \\
d_{2}(\mathrm{~m})\end{array}$ & 0.90 \\
\hline $\begin{array}{l}\text { Distance from passenger3's seat to centre of gravity } \\
d_{3}(\mathrm{~m})\end{array}$ & 4.98 \\
\hline $\begin{array}{l}\text { Distance from passenger's seat above rear axle to } \\
\text { centre of gravity of empty bus } b(\mathrm{~m})\end{array}$ & 1.95 \\
\hline Mass parameters of the bus & Values \\
\hline Sprung mass of fully loaded/empty bus $m(\mathrm{~kg})$ & $15399 / 9399.4$ \\
\hline Front axle mass $m_{t 1}(\mathrm{~kg})$ & 745.6 \\
\hline Rear axle mass $m_{t 2}(\mathrm{~kg})$ & 1355 \\
\hline $\begin{array}{l}\text { Suspended mass moment of inertia of fully } \\
\text { loaded/empty bus relative to the } y \text {-axis } J_{y}\left(\mathrm{kgm}^{2}\right)\end{array}$ & $150000 / 115000$ \\
\hline Oscillatory parameters of the bus & Values \\
\hline Front axle single air bag stiffness $k_{s 1}(\mathrm{~N} / \mathrm{m})$ & 175000 \\
\hline Front axle equivalent air bags stiffness $k_{f}(\mathrm{~N} / \mathrm{m})$ & 350000 \\
\hline Rear axle single air bag stiffness $k_{s 2}(\mathrm{~N} / \mathrm{m})$ & 200000 \\
\hline Rear axle equivalent air bags stiffness $k_{r}(\mathrm{~N} / \mathrm{m})$ & 800000 \\
\hline Single tyre stiffness on the front/rear axle $k_{t 1}(\mathrm{~N} / \mathrm{m})$ & 1000000 \\
\hline Equivalent tyre stiffness on the front axle $k_{f t}(\mathrm{~N} / \mathrm{m})$ & 2000000 \\
\hline Equivalent tyre stiffness on the rear axle $k_{f t}(\mathrm{~N} / \mathrm{m})$ & 4000000 \\
\hline Single tyre damping on the front/rear axle $c_{t 1}(\mathrm{Ns} / \mathrm{m})$ & 150 \\
\hline Equivalent tyre damping on the front axle $c_{f t}(\mathrm{Ns} / \mathrm{m})$ & 300 \\
\hline Equivalent tyre damping on the rear axle $c_{r t}(\mathrm{Ns} / \mathrm{m})$ & 600 \\
\hline
\end{tabular}

Eqs. (18) and (19):

$$
\begin{aligned}
f & =n V ; \\
\Phi_{\zeta}(f) & =\frac{1}{V} \Phi_{\zeta}(n) ;
\end{aligned}
$$

where $f$-temporal frequency of excitation $(\mathrm{Hz}) ; V$-vehicle constant speed $(\mathrm{m} / \mathrm{s})$. The PSD in the function of temporal frequency of excitation can be expressed by Eq. (20):

$$
\Phi_{\zeta}(f)=V^{w-1} \Phi_{\zeta}\left(n_{0}\right) \cdot\left(\frac{f}{n_{0}}\right)^{-w} ;
$$

where $\Phi_{\zeta}(f)$ - PSD of road roughness $\left(\mathrm{m}^{2} / \mathrm{Hz}\right)$.

Figure 9 shows PSDs in the function of temporal frequency for different waviness values and for a constant vehicle speed of $100 \mathrm{~km} / \mathrm{h}$. The PSDs were shown for the temporal frequency

\begin{tabular}{|c|c|}
\hline Seat-human model parameters & Values \\
\hline Head and neck $m_{h i},(i=1 \div 3)(\mathrm{kg})$ & 5.31 \\
\hline Chest and upper torso $m_{c i},(i=1 \div 3)(\mathrm{kg})$ & 28.49 \\
\hline Lower torso $m_{l t i},(i=1 \div 3)(\mathrm{kg})$ & 8.62 \\
\hline Thighs and pelvis $m_{t p i},(i=1 \div 3)(\mathrm{kg})$ & 12.78 \\
\hline Cervical spine damping $c_{1}(\mathrm{Ns} / \mathrm{m})$ & 400 \\
\hline Thoracic spine damping $c_{2}(\mathrm{Ns} / \mathrm{m})$ & 4750 \\
\hline Lumbar spine damping $c_{3}(\mathrm{Ns} / \mathrm{m})$ & 4585 \\
\hline Buttocks damping $c_{4}(\mathrm{Ns} / \mathrm{m})$ & 2064 \\
\hline Seat cushion damping $c_{s c}(\mathrm{Ns} / \mathrm{m})$ & 220 \\
\hline Equivalent damping $c_{4}^{\prime}(\mathrm{Ns} / \mathrm{m})$ & 198.81 \\
\hline Cervical spine stiffness $k_{1}(\mathrm{~N} / \mathrm{m})$ & 310000 \\
\hline Thoracic spine stiffness $k_{2}(\mathrm{~N} / \mathrm{m})$ & 183000 \\
\hline Lumbar spine stiffness $k_{3}(\mathrm{~N} / \mathrm{m})$ & 162800 \\
\hline Buttocks stiffness $k_{4}(\mathrm{~N} / \mathrm{m})$ & 90000 \\
\hline Seat cushion stiffness $k_{s c}(\mathrm{~N} / \mathrm{m})$ & 20000 \\
\hline Equivalent stiffness $k_{4}^{\prime}(\mathrm{N} / \mathrm{m})$ & 16364 \\
\hline
\end{tabular}
range $0.5-50 \mathrm{~Hz}$, since these mostly affected the vehicle's
Table 3. Parameters for seat-human model.

Table 4. Values of statistical parameters for vertical accelerations from measurements and simulation.

\begin{tabular}{|c|c|c|c|c|}
\hline Statistical & \multicolumn{2}{|c|}{ Bus floor (below pass. seat) } & \multicolumn{2}{|c|}{ Passenger's seat } \\
\cline { 2 - 5 } parameters & Measurement & Simulation & Measurement & Simulation \\
\hline Maximum value & 3.35 & 1.3606 & 1.80 & 1.2581 \\
Minimum value & -3.69 & -2.1108 & -1.50 & -1.4469 \\
Mean value & 0.04 & -0.0040 & 0.00 & -0.0052 \\
Dispersion & 0.32 & 0.2664 & 0.45 & 0.2526 \\
\hline
\end{tabular}

oscillatory movement. ${ }^{16}$ The unevenness index $\Phi_{\zeta}\left(f_{0}\right)$ in the function of the reference temporal frequency $f_{0}$ is denoted in Fig. 9.

Values of the important parameters taken for longitudinal road roughness generation are shown in the Table 5.

\subsection{Road Roughness Modelling}

Road roughness in good condition for a vehicle speed of $100 \mathrm{~km} / \mathrm{h}$ was modelled by PSD for A/B road class in ISO 8608. Single-track road roughness can be represented by an infinite sum of harmonic cosine functions of different amplitudes, circular frequencies, and phase angles. Sekulic et al. presented a detailed description of the road modelling process. ${ }^{17}$

Table 5. Parameters for longitudinal road roughness generation.

\begin{tabular}{|c|c|c|c|c|}
\hline \multicolumn{2}{|c|}{$\begin{array}{c}\text { Reference } \\
\text { frequency }\end{array}$} & \multicolumn{2}{|c|}{ Unevenness index } & $\begin{array}{c}\text { Waviness } \\
\text { parameter }\end{array}$ \\
\hline$n_{0}(\mathrm{c} / \mathrm{m})$ & $f_{0}(\mathrm{~Hz})$ & $\Phi_{\zeta}\left(n_{0}\right)\left(\mathrm{m}^{2} /(\mathrm{c} / \mathrm{m})\right)$ & $\Phi_{\zeta}\left(f_{0}\right)\left(\mathrm{m}^{2} / \mathrm{Hz}\right)$ & $w(-)$ \\
\hline 0.1 & 2.7778 & $32 \cdot 10^{-6}$ & $1.152 \cdot 10^{-6}$ & $\begin{array}{c}1.5 ; 2.0 ; 2.5 ; \\
3.0 ; 3.5\end{array}$ \\
\hline
\end{tabular}




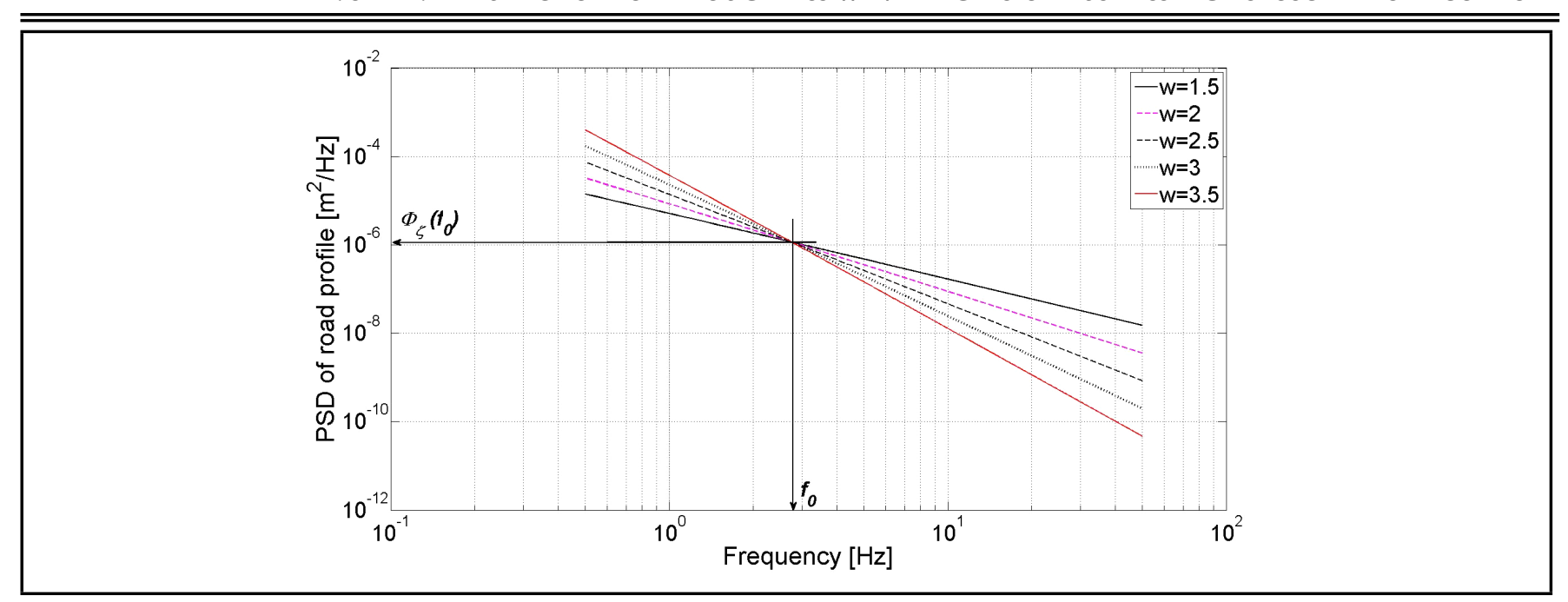

Figure 9. PSD for A/B road class in function of temporal frequency and different value of waviness $w$.

Figure 10 shows longitudinal road roughness in good condition for bus speed of $100 \mathrm{~km} / \mathrm{h}$ in function of waviness $w$. The amplitude of roughness increased with the increase in the parameter $w$ (Fig. 10). For a waviness value of 1.54, the road as a whole looked flat, but had pronounced short wavelengths with amplitudes in the range $\pm 0.010 \mathrm{~m}$. On the other hand, a road with a high waviness value of 3.5 was uneven with maximum roughness amplitudes in the range from $-0.04 \mathrm{~m}$ to $+0.03 \mathrm{~m}$. However, such road unevenness on short wavelengths were insignificant.

\section{STANDARD ISO 2631/1997}

The international standard ISO 2631/1997 "Mechanical vibration and shock-Evaluation of human exposure to wholebody vibration" described the methods to measure, quantify, and evaluate the effect of random vibrations on human health, comfort, perception, and motion sickness. ${ }^{18}$ This standard was applied to the vibrations acting on the human body in the standing/seated/recumbent positions.

The paper analysed the effect of vertical vibrations on the ride comfort of three passengers for two receiving points (seat and bus floor under the passenger's seat). The relevant value for ride comfort assessing, according to ISO 2631/1997, was the overall vibration total value (Eq. (21)).

$$
\begin{aligned}
\ddot{z}_{w, R M S_{\_} \text {total }}= & \left(\left(k_{z, \text { seat }} \cdot \ddot{z}_{w, R M S_{-} \text {seat }}\right)^{2}+\right. \\
& \left.\left(k_{z, \text { floor }} \cdot \ddot{z}_{w, R M S_{\text {floor }}}\right)^{2}\right)^{1 / 2} ;
\end{aligned}
$$

where $\ddot{z}_{w, R M S \_t o t a l}$ was the overall $R M S$ total value of the weighted vertical acceleration; $\ddot{z}_{w, R M S_{-} \text {seat }}$ was the $R M S$ of the weighted vertical acceleration acting on the whole

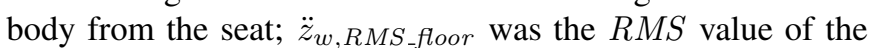
weighted vertical acceleration acting on the passenger's feet from bus floor below the seat; $k_{z, \text { seat }}, k_{z, \text { floor }}$ were the multiplying factors, which values were 1 and 0.4 , respectively.

$R M S$ values of the weighted vertical accelerations $\left(\ddot{z}_{w, R M S_{\text {sseat }},}, \ddot{z}_{w, R M S_{-} \text {floor }}\right)$ were calculated by Eqs. (22) and (23):

$$
\ddot{z}_{w, R M S_{\text {sseat }}}=\sqrt{\frac{1}{T} \int_{0}^{T} \ddot{z}_{w_{\text {sseat }}}^{2}(t) d t}
$$

Table 6. Oscillatory comfort criteria in public means of transport.

\begin{tabular}{|c|c|}
\hline \hline Vibration intensity $\left[\mathrm{m} / \mathrm{s}^{2}\right]$ & Comfort assessment \\
\hline$<0.315$ & not uncomfortable \\
$0.315-0.63$ & a little uncomfortable \\
$0.5-1.0$ & fairly uncomfortable \\
$0.8-1.6$ & uncomfortable \\
$1.25-2.5$ & very uncomfortable \\
$>2.0$ & extremely uncomfortable \\
\hline
\end{tabular}

where $\ddot{z}_{w_{-} \text {seat }}(t), \ddot{z}_{w_{\text {ffloor }}}(t)$ were frequency weighted vertical accelerations for the seat and floor, respectively; and $T$ was the simulation time.

Standard ISO 2631/1997 defined filter $W_{k}$ for weighting of vertical accelerations acting on human body in seated position and on legs (Fig. 11). The analytical expressions for filter $W_{k}$ can be found in annex A of this standard. According to these expressions, the function for acceleration weighting was defined in Matlab software.

Table 6 presents oscillatory comfort criteria in public means of transport according to ISO 2631/1997.

\section{SIMULATOIN RESULTS AND DISCUSSION}

In the paper, vertical acceleration of mass $m_{t p i},(i=1 \div 3)$ were analysed since these accelerations presented an indicator of passengers exposure to WBV coming from the seats (Fig. 12(a,b,c)). The acceleration amplitude for each passenger increased with an increase in parameter $w$. Passengers in the rear part of the bus (passenger 3 ) had a greater value of vertical acceleration for $w=3.5$ (peak minimum/maximum values approximately amount to $\left.\pm 4 \mathrm{~m} / \mathrm{s}^{2}\right)$.

The oscillatory comfort was also influenced by the vibrations acting on the passengers' legs from the bus floor. Acceleration amplitude from bus floor increased with an increase in parameter $w$ (Fig. 12(d,e,f)). The greater values were for the rear part of the bus (peak minimum/maximum values approximately amounted to $\pm 3 \mathrm{~m} / \mathrm{s}^{2}$ for $w=3.5$ ).

Figure 13 shows values of equivalent damping forces for the front/rear axle used in the simulation. Max/min values of relative piston velocity was around $\pm 0.5 \mathrm{~m} / \mathrm{s}^{2}$ for both bus axles. 


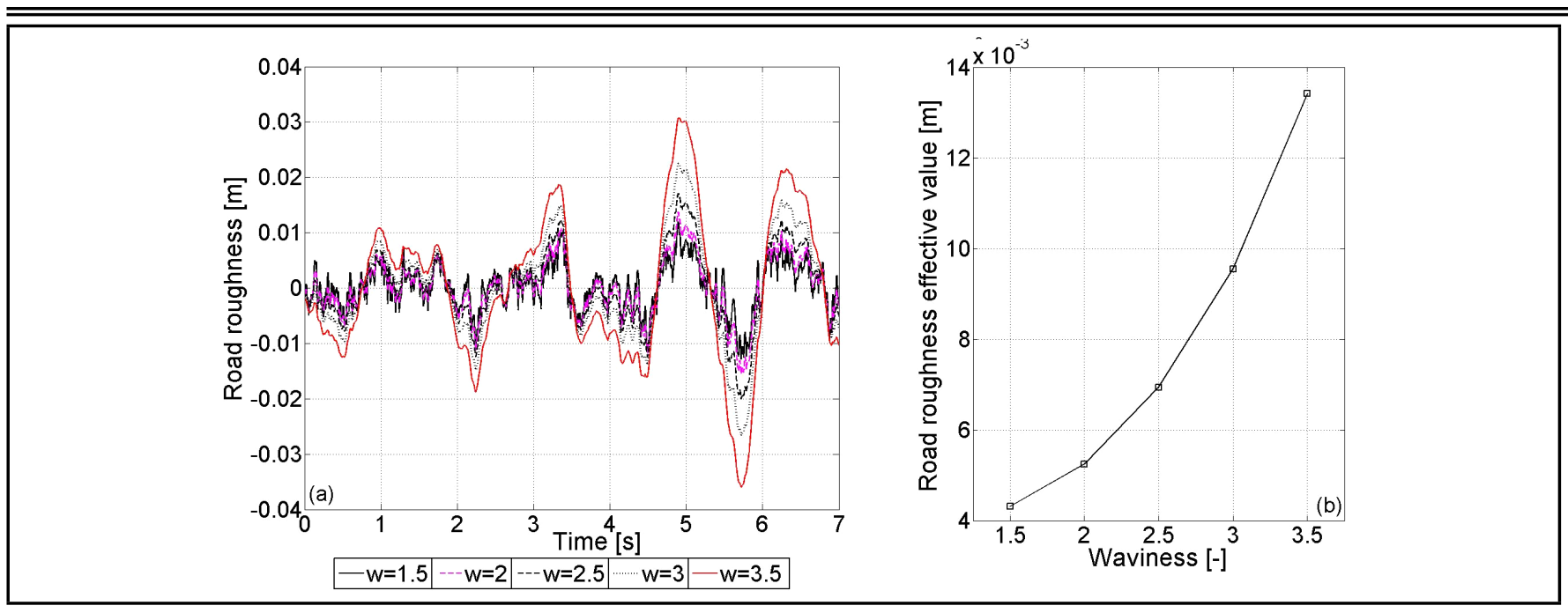

Figure 10. Roughness of A/B road class according to ISO 8608 a) in function of time, b) effective values, for different parameter $w$.

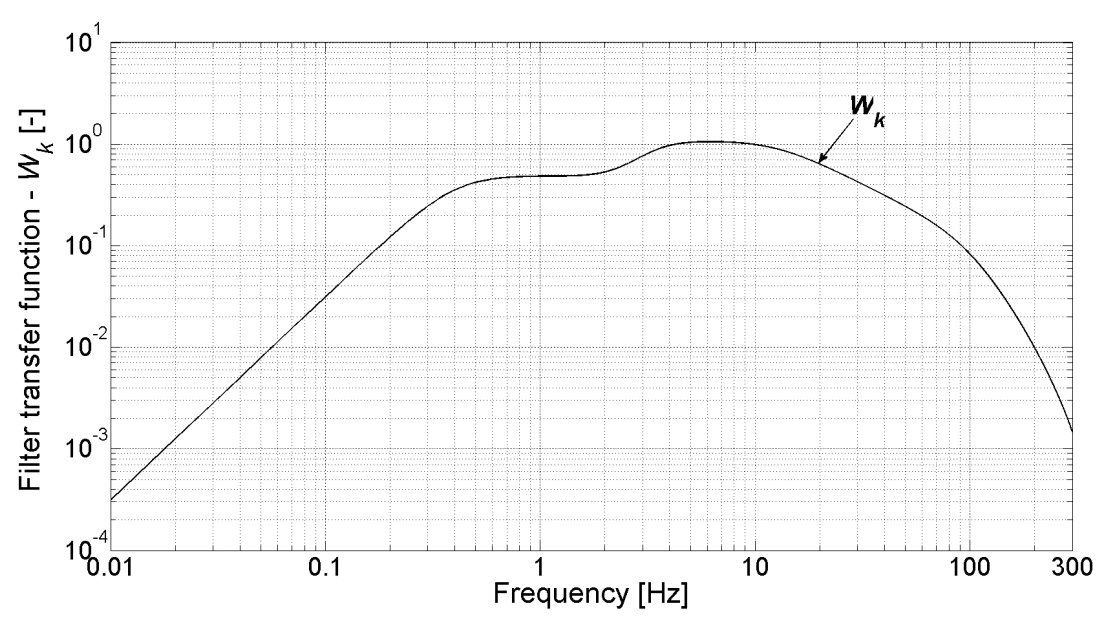

Figure 11. Filter $W_{k}$ for vertical acceleration weighting.

\subsection{Analysis of Constrained Forces Between Passengers' Bodies and Their Seats}

The constrained force between passenger body and the seat was comprised of a static and dynamic part, as follows:

$$
\begin{aligned}
F(t)= & F_{s t}+F_{d y n}(t) \\
= & \left(m_{h i}+m_{c i}+m_{l t i}+m_{t p i}\right)+k_{4}^{\prime}\left(z_{j}-z_{t p i}\right) \\
& \quad(i=1 \div 3 ; \quad j=A, B, C) ;
\end{aligned}
$$

where $F_{s t}$ was a static force $(\mathrm{N})$, and $F_{d y n}(t)$ was a dynamic force $(\mathrm{N})$. The dynamic part could have positive and negative values. Total constrained force was equal to zero when $F_{d y n}(t)=-F_{s t}$ and there had been a loss of contact between the passenger body and the seat. Figure 14 shows constrained forces in function of time for every passenger. The total forces had positive values, meaning that contact had not been lost. Total forces were of the greatest values for the waviness parameter $w=3.5$. Static force has also been denoted in the Fig. 14.

Figure 15(a) comparatively shows road roughness excitation for waviness parameter value $w=3.5$ and two bus speeds (speed of $100 \mathrm{~km} / \mathrm{h}$ and a maximum speed of $130 \mathrm{~km} / \mathrm{h}$ ). Figure 15(b-c) shows the constrained forces for the bus passengers. Although the magnitudes of the total forces for the maximum bus speed noticeably changed compared to those for a speed of $100 \mathrm{~km} / \mathrm{h}$, forces were still positive values (Fig. 15(c)). For the maximum bus speed and road roughness in good condition, passenger bodies were in permanent contact with their seats. Permanent contact between passengers' bodies and their seats was a prerequisite for using the differential equations of motion (Eqs. (1-10)) for the defined bus oscillatory model.

\subsection{Analysis of Passengers' Oscillatory Comfort}

Table 7 shows $R M S$ values of raw vertical acceleration for bus floor and passengers' seats in the function of parameter $w$. The $R M S$ acceleration values for every seat increased with an increase in parameter $w$. The $R M S$ acceleration values for bus floor first decreased, and then increased with the increase in parameter $w$. The $R M S$ acceleration values for seats were greater compared to the bus floor for $w=2.5 \div 3.5$.

Figure 16 shows PSDs of vertical accelerations acting on passengers' bodies. The PSDs were obtained according to the Welch method implemented by the "pwelch" function in the Matlab Signal Processing Toolbox. ${ }^{19}$ Intesites of PSDs increased with an increase in parameter $w$. Passenger 3 had the greatest PSD value, approximately to $1.6\left(\mathrm{~m} / \mathrm{s}^{2}\right)^{2} / \mathrm{Hz}$ for 


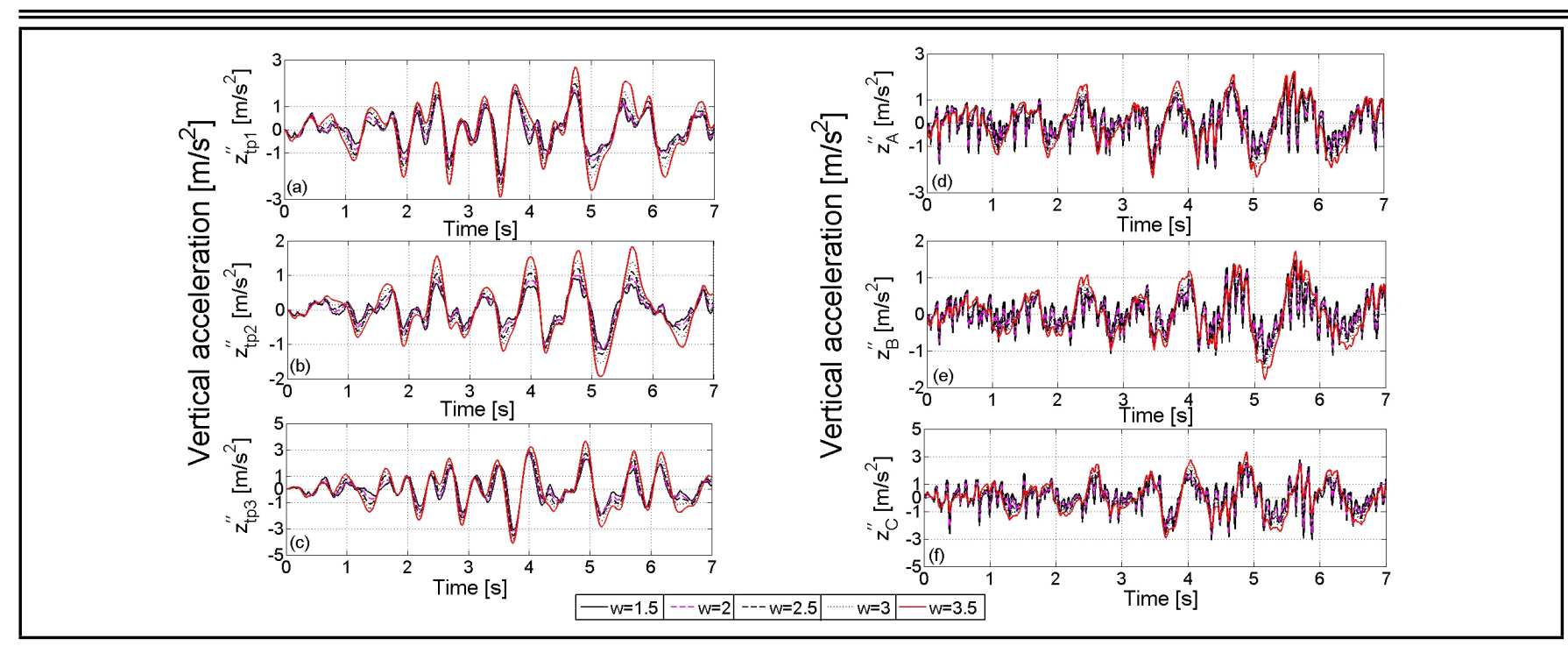

Figure 12. Vertical acceleration for a) passenger 1's seat, b) passenger 2's seat, c) passenger 3's seat, d) floor below passenger 1's seat, e) floor below passenger 2's seat, f) floor below passenger 3's seat, in function of parameter $w$.
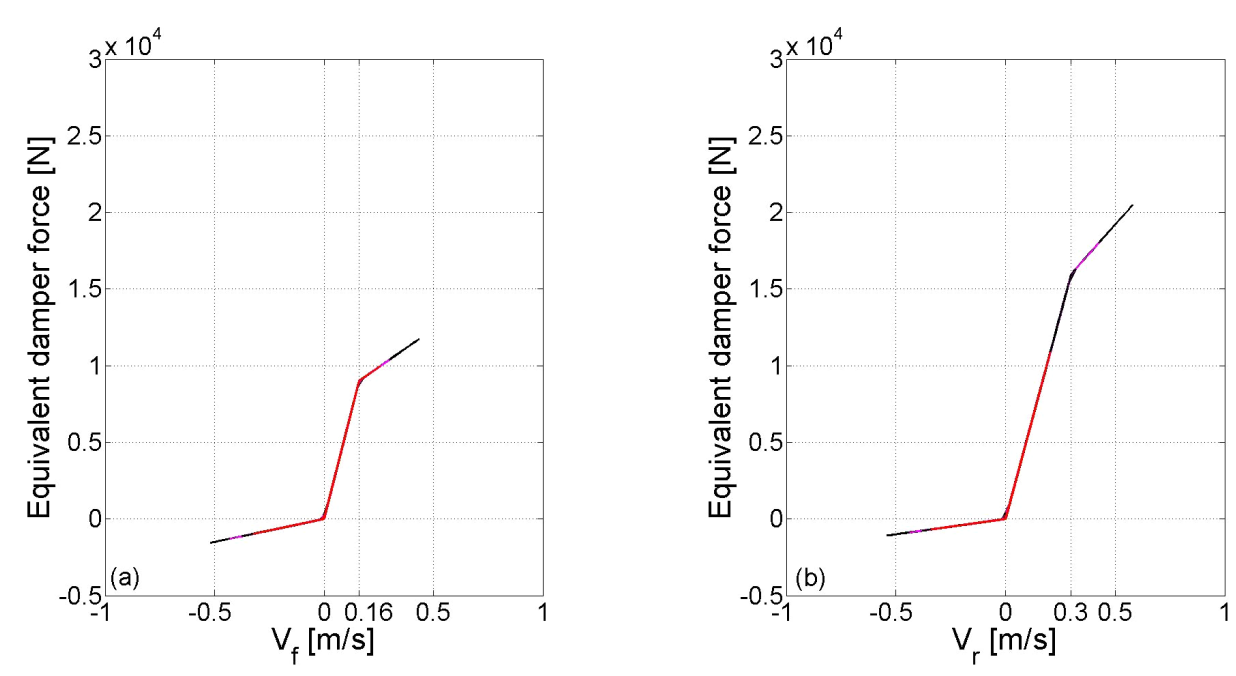

Figure 13. Equivalent damping forces used in simulation for a) front, b) rear bus axle.

$w=3.5$. Vibration intensities were distributed in the frequency range $0 \div 4 \mathrm{~Hz}$. The maximum values of PSDs for all passengers were at $1.2 \mathrm{~Hz}$. The seats attenuated vertical vibrations at frequencies above $4 \mathrm{~Hz}$.

Figure 17 shows the PSDs of vertical accelerations from the bus floor below the passengers' seats. Vibrational intensities were mainly distributed into two frequency ranges, $0 \div 2.5 \mathrm{~Hz}$ and $5 \div 10 \mathrm{~Hz}$. The higher vibrational intensities corresponded to a lower frequency range. The intensities of the vertical acceleration increased in the lower frequency range, whereas in the higher frequency range intensities decreased with an increase in parameter $w$.

Figure 18(a) shows $R M S$ values of the weighted vertical acceleration for passengers' seats and bus floor in function of parameter $w$. The $R M S$ values for the seats increased with an increase in parameter $w$. The greater $R M S$ values corresponded to parameter $w=3.5$, and the lowest to $w=1.5$. On the other hand, the $R M S$ values from bus floor decreased with an increase in parameter $w$. The lowest $R M S$ values corresponded to waviness $w=3$, and the greatest to waviness $w=1.5$.

Figure 18(b) shows the change in the total $R M S$ value of the weighted vertical acceleration in function of parameter $w$. For every passenger, the total $R M S$ value increased with an increase in parameter $w$. For passenger 1, the $R M S$ value was greater than $0.5 \mathrm{~m} / \mathrm{s}^{2}$ for the parameter $w$ above 2.5 . For passenger 2 , the $R M S$ value was greater than $0.315 \mathrm{~m} / \mathrm{s}^{2}$ for the parameter $w$ above 2.7. For passenger 3, the $R M S$ value was greater than $0.8 \mathrm{~m} / \mathrm{s}^{2}$ for the parameter $w$ above 3.3 .

Table 8 shows total $R M S$ values and comfort assessment for every passenger in function of parameter $w$. Passenger 2 had the best comfort, and the worst was passenger 3 . For the unevenness parameter values of $w=3,3.5$, comfort for passenger 2 corresponded to a 'little uncomfortable'. The comfort assessment for passenger 3 for $w=3.5$ corresponded to 'uncomfortable'. The passenger in the front part of the bus had better oscillatory comfort than the passenger in the rear part of the bus.

These results indicated that the waviness parameter $w$ affected the oscillatory comfort of the bus users. This fact should be considered when designing buses, and especially oscillatory parameters of the systems that have significant impact on the bus ride comfort (e.g. elastic bus suspension system, passenger seat cushion, etc.). 


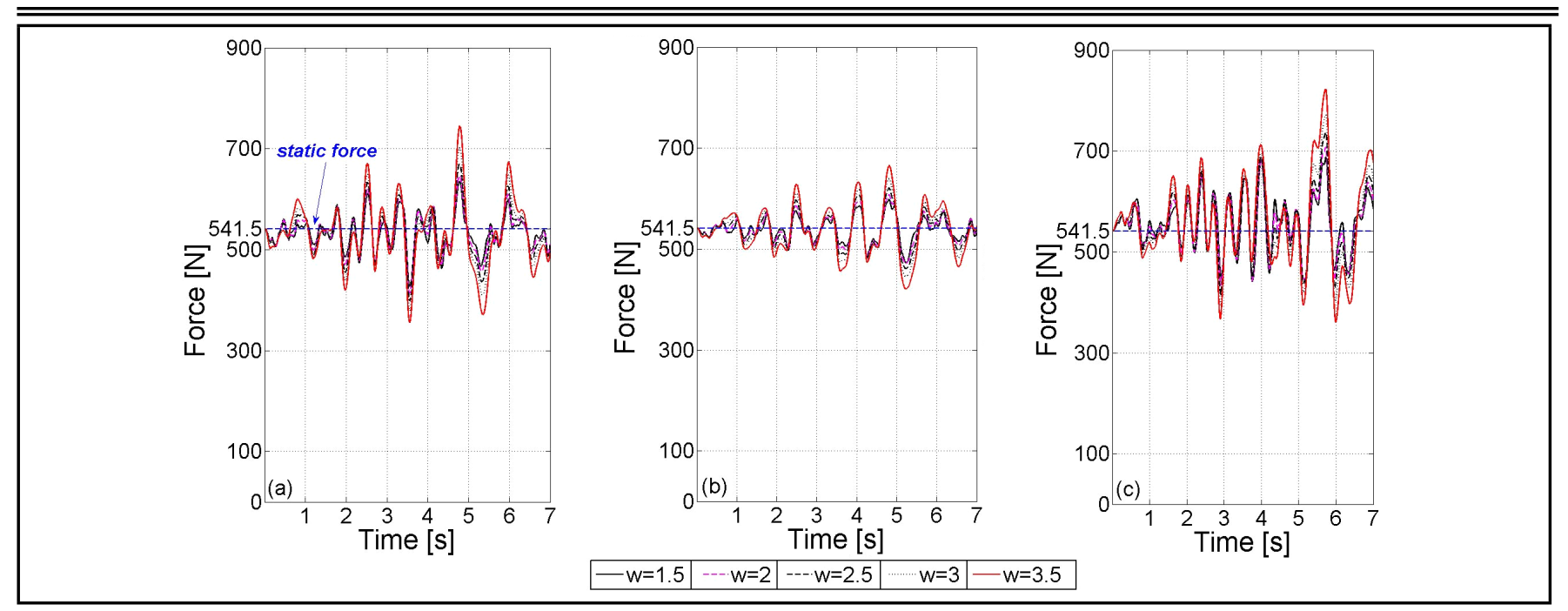

Figure 14. Constrained forces between passenger's body and the seat in function of time for a) passenger 1, b) passenger 2, c) passenger 3 .
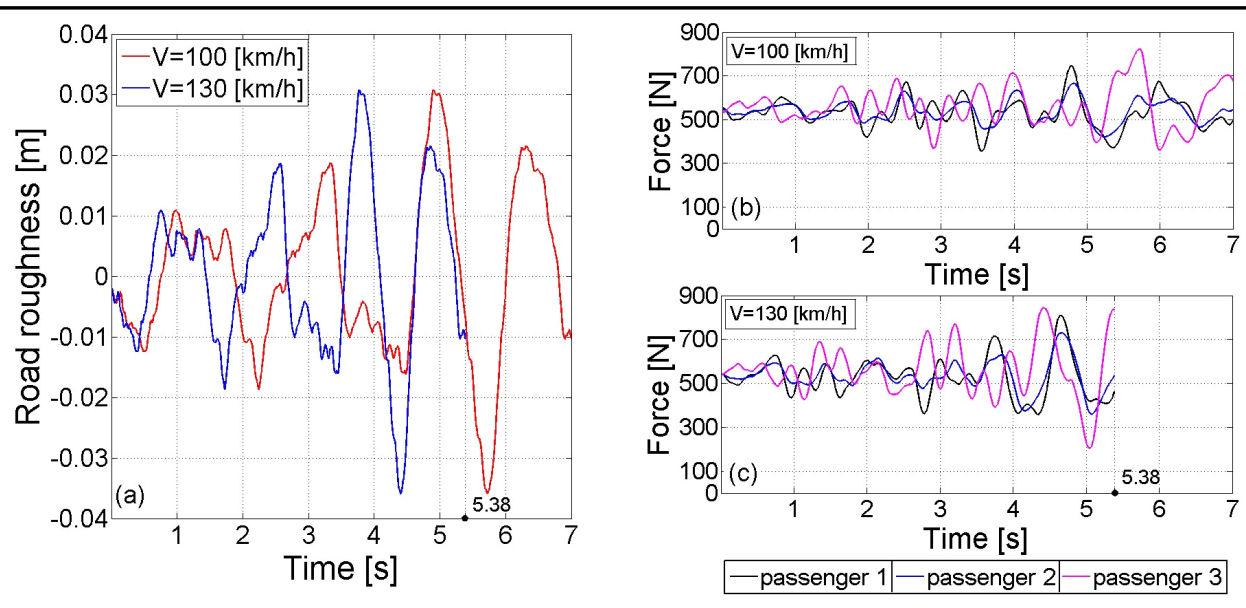

Figure 15. Change in a) road roughness in good condition for different bus speeds, b) constrained forces for speed of $100 \mathrm{~km} / \mathrm{h}$, c) constrained forces for speed of $130 \mathrm{~km} / \mathrm{h}$.

Figure 19(a) shows the change in parameter $S E A T_{R M S}$ in the function of the parameter $w$ for the bus passengers. The parameter $S E A T_{R M S}$ indicated an isolation characteristic of the seats equipped with different suspension systems when excited with the same input signals. ${ }^{20}$ Although all passenger seats have the same seat cushion oscillatory parameters, the bus floor excitations are not the same. In this paper, the parameter $S E A T_{R M S}$ assessed the isolation characteristics of the users' seats in the function of their position on the bus platform.

$S E A T_{R M S}$ parameter can be calculated by following Eq. (25):

$$
\begin{aligned}
S E A T_{R M S}[\%] & =\frac{\ddot{z}_{R M S(w, \text { seat })}}{\ddot{z}_{R M S(w, \text { floor })}} \cdot 100 \\
& =\frac{\left(\frac{1}{T} \int_{0}^{T} \ddot{z}_{w, \text { seat }}^{2}(t) d t\right)^{1 / 2}}{\left(\frac{1}{T} \int_{0}^{T} \ddot{z}_{w, \text { floor }}^{2}(t) d t\right)^{1 / 2}} \cdot 100
\end{aligned}
$$

where $\ddot{z}_{R M S(w, s e a t)}$ and $\ddot{z}_{R M S(w \text {,floor })}$ were $R M S$ values of the weighted vertical accelerations on the seat and the bus floor below the seat.

A $S E A T_{R M S}$ value greater than $100 \%$ indicates that the seat amplified bus floor vibrations. If the $S E A T_{R M S}$ value was equal to $100 \%$, the seat did not isolate floor vibration. The seat attenuated some vibration if $S E A T_{R M S}$ value was less than $100 \%$. $^{21}$

As the parameter $w$ increased, the value of the $S E A T_{R M S}$ parameter increased. The passenger seats attenuated less vibration with the increase in the parameter $w$. Passenger 2 had the lowest values of the $S E A T_{R M S}$. The seat increased the intensities of vertical vibrations for the passenger 1 , passenger 2 and passenger 3 for the values of parameters $w$ greater than $2.7,2.8$ and 2.4 , respectively.

Figure 19(b) shows change in percentage differences $P D_{R M S_{\text {_total }}}(\%)$ for passengers in the function of parameter $w$, according to Eq. (26):

$$
\begin{aligned}
& P D_{R M S \_t o t a l}[\%]= \\
& \quad \frac{\ddot{z}_{w, R M S \_t o t a l(W)}-\ddot{z}_{w, R M S \_t o t a l}(W=2)}{\ddot{z}_{w, R M S \_t o t a l}(W=2)} \cdot 100
\end{aligned}
$$

where $\ddot{z}_{w, R M S_{-} \operatorname{total}(W)}$ was the total $R M S$ value of the weighted vertical acceleration in the function of parameter $w$; $\ddot{z}_{w, R M S_{-} \operatorname{total}(W=2)}$ was the total $R M S$ value of the weighted vertical acceleration for the standard value of the waviness parameter $(w=2)$.

The percentage differences between the $R M S$ value for the waviness $w=1.5 \div 2.3$ and $R M S$ value for nominal waviness $w=2$ was lower than $5 \%$ for each passenger. This indicated 
Table 7. $R M S$ of raw vertical acceleration for bus floor and passengers' seat in function of parameter $w$.

\begin{tabular}{|c|c|c|c|c|c|c|}
\hline \multicolumn{2}{|c|}{ Waviness parameter } & $w=1.5$ & $w=2$ & $w=2.5$ & $w=3$ & $w=3.5$ \\
\hline & Floor below passenger 1 seat & 0.737 & 0.706 & 0.734 & 0.820 & 0.975 \\
$R M S$ value of & Passenger 1-mass $m_{t p 1}$ & 0.662 & 0.723 & 0.822 & 0.959 & 1.149 \\
raw vertical & Floor below passenger 2 seat & 0.459 & 0.446 & 0.471 & 0.535 & 0.647 \\
acceleration & Passenger 2-mass $m_{t p 2}$ & 0.392 & 0.444 & 0.525 & 0.629 & 0.776 \\
$\left(\mathrm{~m} / \mathrm{s}^{2}\right)$ & Floor below passenger 3 seat & 0.967 & 0.916 & 0.946 & 1.049 & 1.224 \\
& Passenger 3-mass $m_{t p 3}$ & 0.961 & 1.025 & 1.129 & 1.278 & 1.485 \\
\hline
\end{tabular}

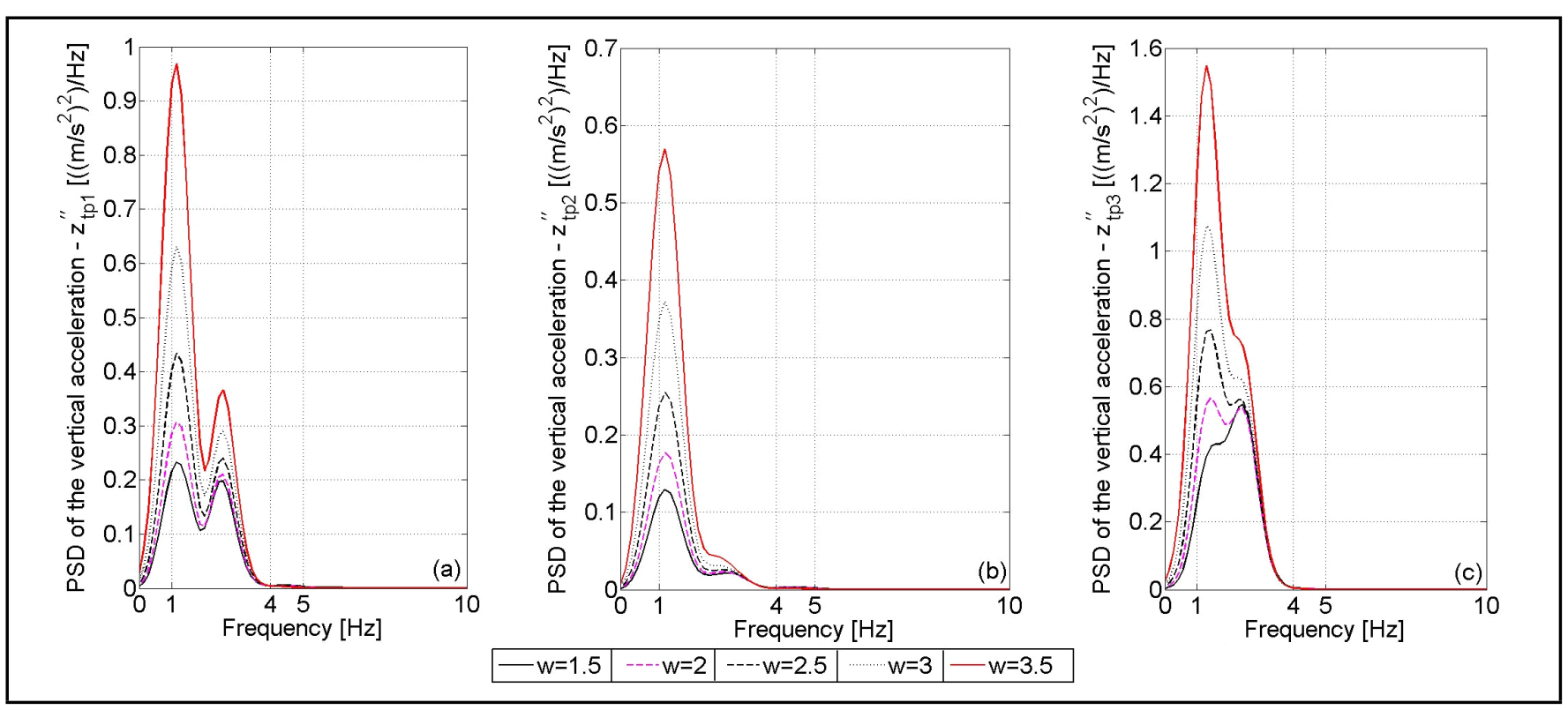

Figure 16. PSDs of the seat vertical acceleration for a) passenger 1, b) passenger 2, c) passenger 3, in function of parameter $w$.

that the parameter $w$ in the specified narrow range for $\mathrm{A} / \mathrm{B}$ road class had similar effect on passengers' comfort as for $w=2$. The standard value of the parameter $w=2$ was precise enough for estimating the comfort of the bus users.

\section{CONCLUSIONS}

In this paper, bus passengers' ride comfort is analysed in the function of the waviness parameter $w$ from range $1.5 \div 3.5$. Vertical acceleration amplitude on the passengers' seats as well as that on the bus floor under the seat increase with the increase in parameter $w$. The intensities of vertical acceleration for passengers' seats are concentrated in the frequency range $0 \div 4 \mathrm{~Hz}$. The acceleration intensities from the bus floor are mainly distributed into two frequency ranges, $0 \div 2.5 \mathrm{~Hz}$ and $5 \div 10 \mathrm{~Hz}$, with higher acceleration intensities in the lower frequency range.

The $R M S$ values of the weighted vertical acceleration from seats increase with the increase in the parameter $w$, and reach the greatest values for $w=3.5$. On the other hand, the $R M S$ values from the bus floor decrease, and reach the lowest values for $w=3$.

The total $R M S$ values of the weighted vertical acceleration increase with the increase in the parameter $w$. The passenger in the rear part of the bus has the worst comfort level, whereas passenger in the middle part has the best. The comfort assessment for the passenger in the bus's middle part for the unevenness parameter values $w=3,3.5$ is 'a little uncomfortable'. The passenger in the rear part of the bus has the greatest total $R M S$ value of $0.835 \mathrm{~m} / \mathrm{s}^{2}$ for parameter $w=3.5$, which corresponds to an 'uncomfortable' comfort assessment.

As the parameter $w$ increases, SEAT RMS parameter value increases. Passenger seats attenuate less vibration with the in- crease in the parameter $w$. The lowest values of the parameter $S E A T_{R M S}$ have a passenger in the bus's middle part. The percentage differences between the $R M S$ of the weighted vertical acceleration for the parameter $w$ in the range $1.5 \div 2.3$, and the standard value $w=2$ is less than $5 \%$ for each passenger. This indicates that the parameter $w$ in the specified narrow range has similar effect on passengers' comfort as for $w=2$.

Although many real road profiles have a non-standard PSD, in the vehicle industry standard PSD with waviness $w=2$ is often used for simulation in the process of dynamic vehicle behaviour investigation. The results of the analysis indicate that wavelengths distribution of the longitudinal road roughness affects oscillatory comfort of the bus users. This fact should be considered when designing buses, and especially the oscillatory parameters of the systems that have significant impact on the bus ride comfort (e.g. elastic bus suspension system, passenger seat cushion, etc.).

The developed oscillatory model in this paper could be used for an investigation of oscillatory comfort not only for intercity buses, but also for the other types of the buses (e.g. city/intercity/tourist buses). Apart from the oscillatory comfort, this model could be useful for analysis of different problems in the area of the bus vertical dynamics, such as analysis of pavement load, deformation of the bus suspension system, and the like.

\section{ACKNOWLEDGEMENTS}

Support for this research was provided by the Ministry of Education, Science and Technological Development of the Republic of Serbia under Grant No. TR36027. This support is gratefully acknowledged. 


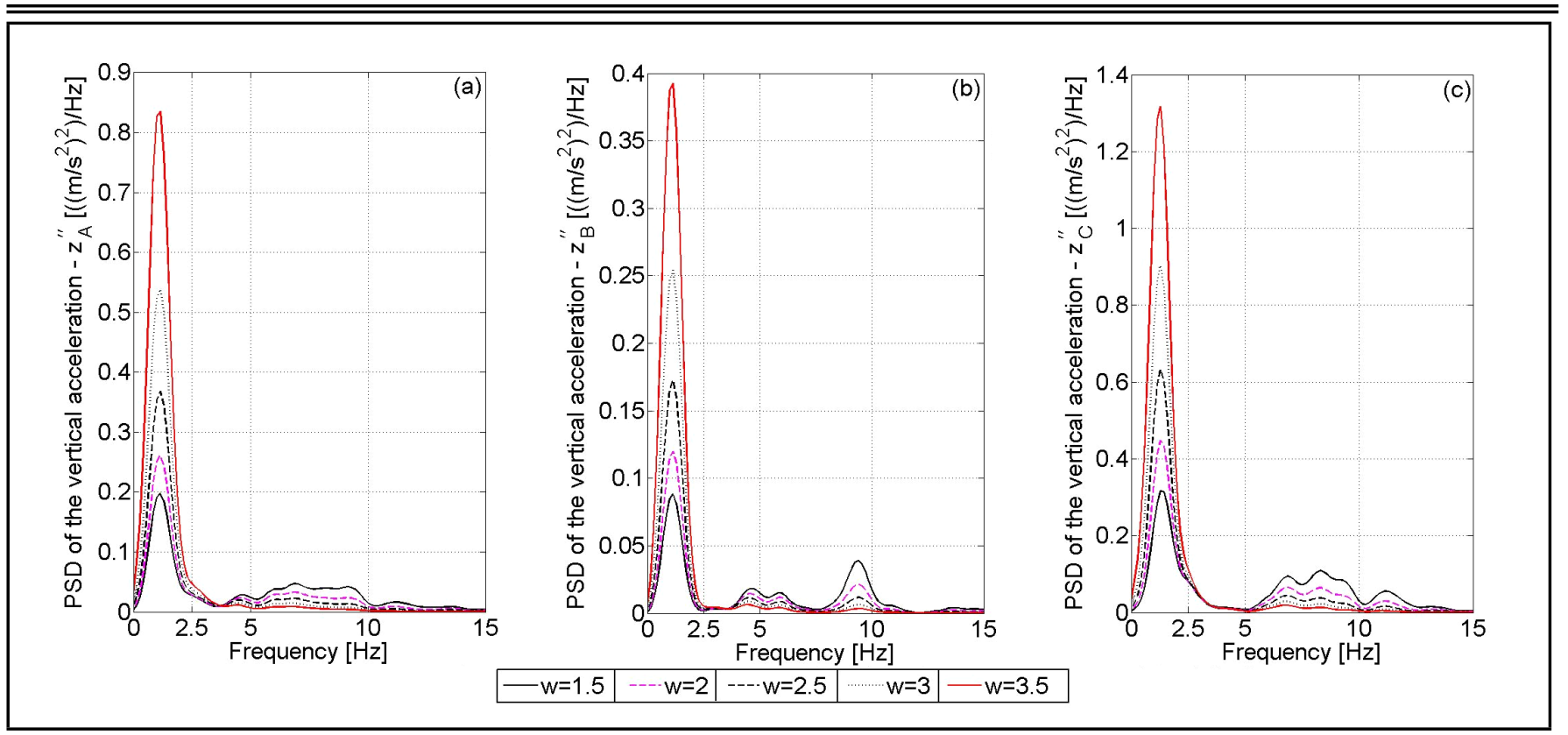

Figure 17. PSDs of the floor vertical accelerations below a) passenger 1's seat, b) passenger 2's seat, c) passenger 3's seat, in function of parameter $w$.
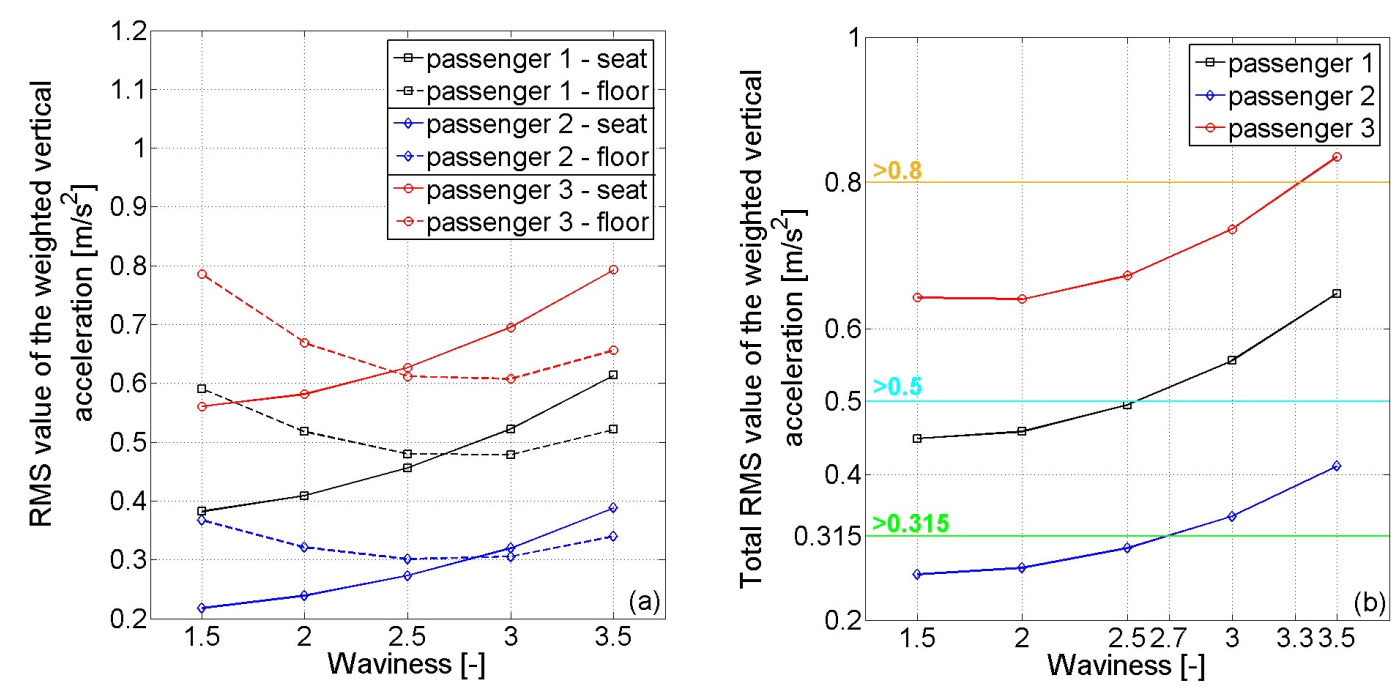

Figure 18. Change in a) $R M S$ value of the weighted vertical acceleration for passengers' seats and bus floor, b) total $R M S$ value of the weighted vertical acceleration, in function of parameter $w$.

\section{REFERENCES}

1 Múčka, P. Current approaches to quantify the longitudinal road roughness, International Journal of Pavement Engineering, 17 (8), 659-679, (2016). https://dx.doi.org/10.1080/10298436.2015.1011782

2 ISO 8608. Mechanical vibration-Road surface profilesReporting of measured data, International Organization for Standardization, Geneva, Switzerland, (1995).

3 Andren, P. Power spectral density approximations of longitudinal road profiles, International Journal of Vehicle Design, 40 (1-3), 2-14, (2006). https://dx.doi.org/10.1504/IJVD.2006.008450

4 Múčka, P. Road waviness and the dynamic tyre force, International Journal of Vehicle Design, 36 (2-3), 216-232, (2004). https://dx.doi.org/10.1504/IJVD.2004.005357
5 Múčka, P. The influence of the road profile wavelengths on vehicle vibration, Contents of Journal of Mechanical Engineering, 53 (6), 357-378, (2002).

6 Steinauer, B. and Ueckermann, A. Die Längsunebeheit auch die Beanspruchung für die Strasse und Fahrer, Strasse und Autobahn, 52 (8), 445-454, (2001).

7 Nahvi, N., Fouladi, M. H., and Nor, M. J. M. Evaluation of whole-body vibration and ride comfort in a passenger car, International Journal of Acoustics and Vibration, 14 (3), 143-149, (2009).

8 Nijemcevic, S., Dragojlovic, D., Zecevic, S., Milosavljevic, B., Cuk, J., and Markovic, S. Technical-selling Book (in Serbian), Ikarbus AD, Belgrade, (2001).

9 Siddiqui, O. M. Dynamic analysis of a modern urban bus for assessment of ride quality and dynamic wheel load, 
Table 8. Comfort assessment for the bus passengers in function of parameter $w$.

\begin{tabular}{|c|c|c|c|c|c|c|}
\hline \multicolumn{2}{|c|}{ Waviness parameter } & $w=1.5$ & $w=2$ & $w=2.5$ & $w=3$ & $w=3.5$ \\
\hline Passenger 1 & $\begin{array}{c}\text { Total } R M S \text { value }\left(\mathrm{m} / \mathrm{s}^{2}\right) \\
\text { Comfort assessment }\end{array}$ & $\begin{array}{c}0.449 \\
\text { a little } \\
\text { uncomfortable }\end{array}$ & $\begin{array}{c}0.459 \\
\text { a little } \\
\text { uncomfortable }\end{array}$ & $\begin{array}{c}0.495 \\
\text { a little } \\
\text { uncomfortable }\end{array}$ & $\begin{array}{c}0.556 \\
\text { fairly } \\
\text { uncomfortable }\end{array}$ & $\begin{array}{c}0.648 \\
\text { fairly } \\
\text { uncomfortable }\end{array}$ \\
\hline
\end{tabular}

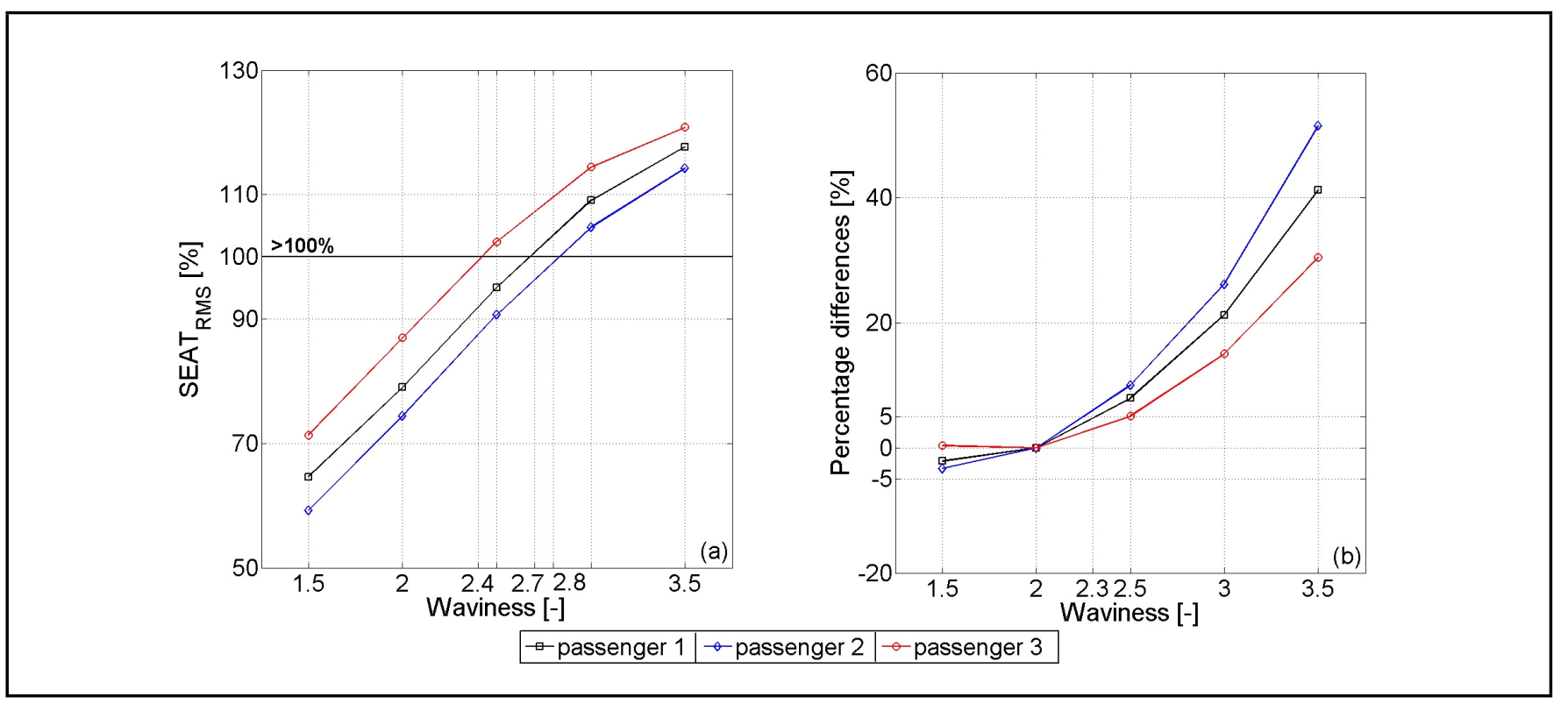

Figure 19. Change in a) parameter $S E A T_{R M S}$, b) percentage differences, for bus passengers in function of parameter $w$.

master's thesis, Concordia University Montreal, Quebec, Canada, (2000).

10 Boileau, P. A study of secondary suspension and human driver response to whole-body vehicular vibration and shock, doctoral dissertation, Concordia University, Canada (1995).

11 Demic, M. and Diligenski, Đ. Theoretical basis of the buses design (in Serbian), Faculty of Mechanical Engineering, Kragujevac, (2003).

12 Diligenski, Đ., Demic, M., and Sakota, Z. Bus passenger vibrational comfort (in Serbian), MVM Monograph, Faculty of Mechanical Engineering, Kragujevac, (2005).

13 Mladenović, D. Bus dynamic behaviour in real driving conditions, doctoral dissertation, University of Belgrade, Faculty of Transport and Traffic Engineering, Serbia, (2008).

14 Data on Roadway Roughnesses (in Serbian), Faculty of Civil Engineering, University of Belgrade, Serbia. (2012).

15 Kropác, O. and Múčka, P. Effects of longitudinal road waviness on vehicle vibration response, Vehicle System Dynamics, 47 (2), 135-153, (2009). https://dx.doi.org/10.1080/00423110701867299

16 Kawamura, A. and Kaku, T. An evaluation of road roughness and the effects on riding comfort and vehicle dy- namics, Doboku Gakkai Ronbunshu, 1985 (359), 137-147, (1985). https://dx.doi.org/10.2208/jscej.1985.359_137

17 Sekulic, D., Dedovic, V., Rusov, S., Salinic, S., and Obradovic, A. Analysis of vibration effects on the comfort of intercity bus users by oscillatory model with ten degrees of freedom, Applied Mathematical Modelling, 37 (18), 8629-8644, (2013). https://dx.doi.org/10.1016/j.apm.2013.03.060

18 ISO 2631. Mechanical vibration and shock e evaluation of human exposure to whole body vibration, Part 1: general requirements, International Standards Organization, Switzerland, (1997).

19 MathWorks, Inc. Signal Processing Toolbox User's Guide, The MathWorks, U.S.A., (2001).

20 Ahmadian, M., Seigler, T. M., Clapper, D., and Sprouse, A. A comparative analysis of air-inflated and foam seat cushions for truck seats, SAE International Truck and Bus Meeting and Exhibition, Detroit, Michigan, (2002). https://dx.doi.org/10.4271/2002-01-3108

21 Basri, B. and Griffin, J. M. The application of SEAT values for predicting how compliant seats with backrests influence vibration discomfort, Applied Ergonomics, 45 (6), 1461-1474, (2014). https://dx.doi.org/10.1016/j.apergo.2014.04.004 